\title{
Status report on the sexual and reproductive health of adolescents living in urban slums in Kenya
}

Donatien Beguy

Joyce Mumah

Salome Wawire

Kanyiva Muindi

Lindsey Gottschalk

See next page for additional authors

Follow this and additional works at: https://knowledgecommons.popcouncil.org/departments_sbsr-rh

Part of the Demography, Population, and Ecology Commons, Family, Life Course, and Society Commons, Gender and Sexuality Commons, Inequality and Stratification Commons, International Public Health Commons, Maternal and Child Health Commons, and the Women's Health Commons How does access to this work benefit you? Let us know!

\section{Recommended Citation}

Beguy, Donatien, Joyce Mumah, Salome Wawire, Kanyiva Muindi, Lindsey Gottschalk, and Caroline W. Kabiru. 2013. "Status report on the sexual and reproductive health of adolescents living in urban slums in Kenya," STEP UP Technical Working Paper. Nairobi: African Population and Health Research Center. 


\section{Authors}

Donatien Beguy, Joyce Mumah, Salome Wawire, Kanyiva Muindi, Lindsey Gottschalk, and Caroline W. Kabiru 



\section{Status Report on the Sexual and Reproductive Health of Adolescents Living in Urban Slums in Kenya}

Donatien Beguy ${ }^{1}$, Joyce Mumah ${ }^{1}$, Salome Wawire ${ }^{1}$, Kanyiva Muindi ${ }^{1}$, Lindsey Gottschalk ${ }^{2}$ and Caroline W. Kabiru $^{1}$

${ }^{1}$ African Population and Health Research Center ${ }^{2}$ Johns Hopkins Bloomberg School of Public Health

STEP UP WORKING PAPER (REVISED)

SEPTEMBER 2013

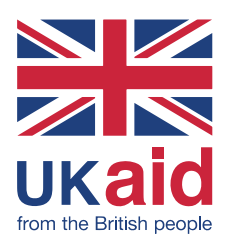


The STEP UP (Strengthening Evidence for Programming on Unintended Pregnancy) Research Programme Consortium generates policy-relevant research to promote an evidence-based approach for improving access to family planning and safe abortion. STEP UP focuses its activities in five countries: Bangladesh, Ghana, India, Kenya, and Senegal. STEP UP is coordinated by the Population Council in partnership with the African Population and Health Research Center; The International Center for Diarrhoeal Disease Research -Bangladesh (icddr-b), the London School of Hygiene and Tropical Medicine; Marie Stopes International; and Partners in Population and Development. STEP UP is funded by UK aid from the UK Government. www.stepup.popcouncil.org

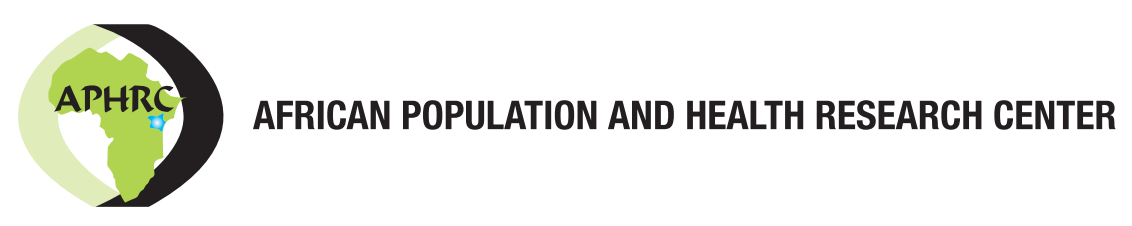

The African Population and Health Research Center, Inc. (APHRC) is an international non-profit, research institute with headquarters in Nairobi, Kenya. APHRC's mission is to be a global center of excellence, consistently generating and delivering relevant scientific evidence for policy and action on population, health, and education in Africa. APHRC brings together a multi-disciplinary team of African scholars to lead the development of priority research programs and enhance the use of research findings for policy formulation and program improvement in sub-Saharan Africa. The Center was established in 1995 as a program of the Population Council and became an autonomous research institution in 2001. www.aphrc.org

Suggested citation: Beguy, D, Mumah, J, Wawire, S, Muindi, K, Gottschalk, L, and Kabiru, C. W. 2013. "Status Report on the Sexual and Reproductive Health of Adolescents Living in Urban Slums in Kenya," STEP UP Technical Working Paper. Nairobi.

\section{(c) 2013 African Population and Health Research Center}

Please address any inquiries about STEP UP to the RPC co-directors:

Dr. Harriet Birungi, hbirungi@popcouncil.org

Dr. Ian Askew, iaskew@popcouncil.org

Funded by

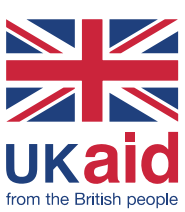




\section{Contents}

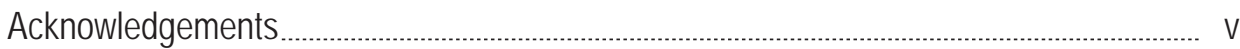

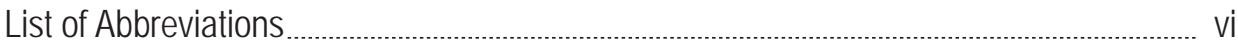

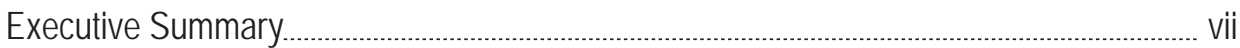

Key Findings .

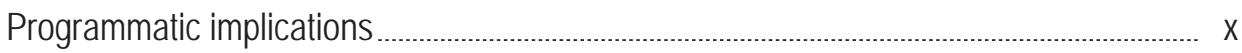

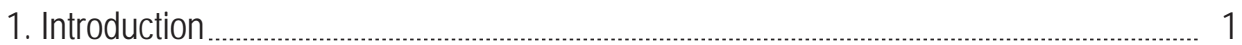

1.1. Background _...

1.2. Methodology

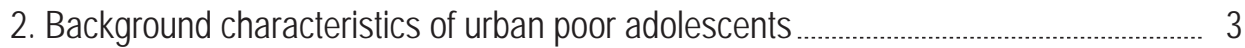

3. Sexual and reproductive health knowledge of urban adolescents ................................. 5

3.1. Awareness and knowledge of the menstrual cycle $\quad 5$

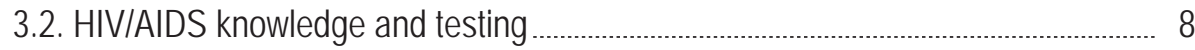

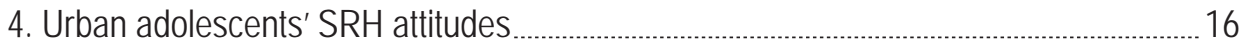

4.1. Attitudes towards sex and contraception ...._....................................... 16

4.2. Intention to use contraception in the future ................................................... 18

4.3. Attitudes towards family $\ldots 19$

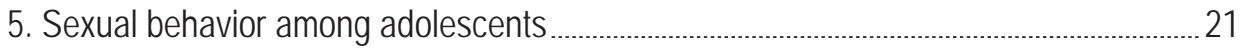

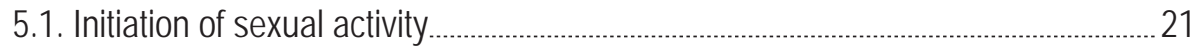

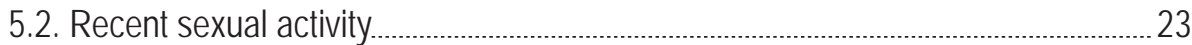

5.3 Circumstances of sexual debut .................................................................. 25

5.4. Circumstances of most recent sexual intercourse _ _

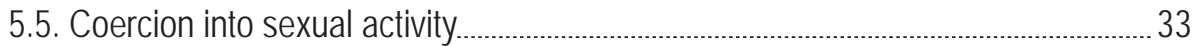

6. Reproductive behavior and unwanted pregnancies ...................................................35

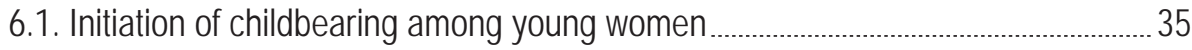

6.2. Experience of unwanted pregnancies ....................................................................... 
7. FP/SRH needs and challenges facing urban adolescents and policy implications _... 39

7.1. Summary and discussion of findings: FP/SRH needs and challenges ..................39

7.2. Policy and programmatic implications

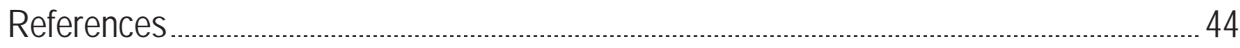




\section{Acknowledgements}

We acknowledge support from the STEP UP (Strengthening Evidence for Programming on Unintended Pregnancy) Research Programme Consortium. STEP UP is funded by the Department for International Development (UKaid). The authors would like to thank Dr. Jean-Christophe Fotso, formerly of the African Population and Health Research Center, for his important contribution to the STEP UP project, and Drs. Chimaraoke Izugbara and Harriet Birungi for their valuable insights and comments on early drafts of this Working Paper.

Findings were based on secondary data from the Transitions-To-Adulthood (TTA) project, which was part of the 5-year project (2006-2010) on Urbanization, Poverty and Health Dynamics, funded by the Wellcome Trust (Grant GR 07830M). This project was nested in the Nairobi Urban Health and Demographic Surveillance System (NUHDSS) which is part of the INDEPTH Network. Analysis and writing time for Donatien Beguy, Joyce Mumah, Caroline Kabiru, and Salome Wawire was supported by funding from the STEP UP project (Grant SR1109D-6), Gates Urban Health Project through a grant from the Bill and Melinda Gates Foundation (Grant OPP1021893) and general support grants to the African Population and Health Research Center from Sida (Reference Number 2011-001578), the William and Flora Hewlett Foundation (Grant Number 2009-4051) and the Rockefeller Foundation (Grant Number 2009SCG302). Donatien Beguy's analysis and writing time was also funded through the Measurement, Learning and Evaluation project (MLE) funded by the Bill \& Melinda Gates Foundation (Grant 52037). 


\section{List of Abbreviations}

$\begin{array}{ll}\text { AIDS } & \text { Acquired Immune Deficiency Syndrome } \\ \text { APHRC } & \text { African Population and Health Research Center } \\ \text { FP } & \text { Family Planning } \\ \text { HIV } & \text { Human Immunodeficiency Virus } \\ \text { NUHDSS } & \text { Nairobi Urban Health and Demographic Surveillance System } \\ \text { PMTCT } & \text { Prevention of Mother to Child Transmission of HIV } \\ \text { SRH } & \text { Sexual and Reproductive Health } \\ \text { STIS } & \text { Sexually Transmitted Infections } \\ \text { TTA } & \text { Transition to Adulthood project } \\ \text { VCT } & \text { Voluntary Counseling and Testing }\end{array}$




\section{Executive Summary}

Young people face numerous health challenges during their transition to adulthood. These challenges include, among others, limited access to sexual and reproductive health (SRH) information and services. Unmet SRH needs among adolescents may contribute to sexually transmitted infections (STIS), including HIV, and unintended pregnancies. Adolescent pregnancies are associated with several adverse outcomes, such as miscarriage, unsafe abortion, obstructed labor, and other complications, which can result in long-term morbidity and even death. Additionally, poor sexual and reproductive health outcomes can especially impact the status of young women, as they may face stigma from the community as well as diminished educational and employment opportunities. The long-term impacts of unmet SRH are also felt at population level, as high prevalence of HIV and high fertility rates place strains on communities and nations. As the world undergoes rapid urbanization, these strains will be increasingly felt in urban populations.

In Kenya, adolescents make up a considerable proportion of urban populations, and many of them live in the numerous informal settlements-or slums-in Nairobi. Adolescents living in the slums face a distinct set of challenges as they transition to adulthood in a hostile environment characterized by high levels of unemployment, crime, poor sanitation, substance abuse, poor education facilities, and lack of recreational facilities. While much has been done to provide insights into adolescents' SRH outcomes in the country, little attention has been paid to understanding and meeting the SRH challenges and needs specific to adolescents living in resource-poor urban settings, such as the slums of Nairobi. This is a priority area for research, as the wellbeing of the urban poor will increasingly drive national development indicators, including health and poverty, in Kenya. This report is based on secondary analysis of data from the Transition to Adulthood (TTA) project among 12-22 years olds living in two informal settlements, Korogocho and Viwandani, in Nairobi, Kenya. The report highlights the SRH challenges faced by adolescents living in these slums, as well as the perceptions and strategies that adolescents adopt to deal with each of these challenges. The findings are expected to contribute guidance to the design and implementation of appropriate SRH intervention programs that respond to the unique needs of adolescent boys and girls living in poor urban settings. 


\section{Key Findings}

Poor knowledge of the menstrual cycle and fertility: Across all groups, $65 \%$ of males and $74 \%$ of females reported being aware of the days when a woman is most likely to be pregnant. When asked to identify the fertile period however, only about one in five females could correctly report that a woman is most fertile halfway between two periods. Unsurprisingly, a higher percentage of older females, married females, and more educated females could correctly identify the fertile period. However, even among those groups, correct knowledge was never higher than one in four females ( $26 \%$ of those with a secondary or higher education).

Universal knowledge of HIVIAIDS: Nearly $100 \%$ of male and female adolescents across all age clusters reported that they had heard of HIVIAIDS. Qualitative interviews also support this finding and suggest that adolescents living in the slums perceive HIVIAIDS as a challenge for their peers in the community.

Substantial age and gender differences in HIV testing experiences: The proportion of adolescents that has ever been tested for HIV increased with age and education. Married adolescents were more likely to have ever been tested for HIV. Females were more likely to have been tested for HIV and were more likely to have been tested in a clinic or hospital than their male counterparts, though this is likely explained by HIV testing for prevention of mother-to-child transmission (PMTCT) during pregnancy. Males were more likely than females to have asked for the test (rather than be asked or be required to take it) and were more likely to have been tested at a voluntary counseling and testing (VCT) center.

Persistence of culturally normative attitudes: Adolescents generally agreed with statements that reinforced cultural norms. A very high percentage of adolescents agree that young men and women should remain virgins until marriage, with a higher percentage of both genders reporting the importance of premarital abstinence for young women. Marriage is considered 'very important' by most adolescents, and the importance increases with age. Slightly more males than females reported that it is 'very important' to get married ( $86 \%$ compared to $80 \%$, respectively). Childbearing was also reported as being 'very important' to $85 \%$ of females and $88 \%$ of males.

Early initiation of sexual activity: Sexual debut before the age of 15 was reported by $11 \%$ of males and $8 \%$ of females; including of adolescents aged 12-14 years who are not yet out of the early initiation window (3\% of males and $4 \%$ of females aged $12-14$ years had already initiated sex). Among males aged $20-22$ years, $19 \%$ reported early sexual debut compared to $12 \%$ of males aged $15-19$, which may indicate a trend towards late sexual debut among males.

Low use of condoms and other contraceptives: Adolescents in the survey and in-depth interviews overwhelmingly reported that they did not use condoms or other contraceptives during their first sexual encounter, citing lack of knowledge as the most common reason for non-use. Among the sexually experienced 12-14 year-olds, none of the males and $15 \%$ of females reported using a condom at first sexual encounter, highlighting one of the reasons why early sexual debut is regarded as risky. 
For both genders, condom use was highest among 15-19 year-olds, perhaps because these adolescents are less likely than older adolescents to be sexually active within a marital relationship. Condom use at last intercourse was twice as high among males, compared to their female counterparts ( $46 \%$ vs. $24 \%$ ).

Condom use for dual protection: Among those adolescents who used a condom at their first sexual encounter, $72 \%$ of males and $75 \%$ of females reported using condoms to guard against both pregnancy and STIS/HIV. Among those who used a condom at their last sexual encounter, $78 \%$ of males and $65 \%$ of females reported condom use for dual protection. This is a promising finding in support of continued marketing of condoms for dual protection although it is important to note that the use of condoms is still very low among adolescents.

Disconnect between adolescents' sexual and reproductive health attitudes and their behavior: Respondents tended to place a high value on abstinence before marriage, yet many still reported engaging in premarital sexual activity. Similarly, the percentage of adolescents who agreed that it is smart to use condoms to prevent HIV, and contraceptives to prevent unplanned pregnancies was much higher than the percentage of adolescents who actually reported using condoms or other contraceptives at their last sexual encounter.

High burden of unwanted and mistimed pregnancies: Thirty-six percent of females' most recent pregnancies were unplanned, with the burden substantially higher among certain subgroups of females. Among the never-married females and females aged 12-14 years, two out of three pregnancies were unplanned; among females aged 15-19 years, a quarter of pregnancies were unwanted and another quarter mistimed. Additionally, nearly every female who reported a pregnancy was out of school. Though our survey question does not capture directionality, this likely reflects the reality that for females, pregnancy is often a reason for dropping out of school.

Threat of unwanted, transactional and coercive sex: About $3 \%$ of young women reported being physically forced or threatened into having sexual intercourse. $2 \%$ of males and $5 \%$ of females reported ever being touched in a sexual manner without their consent. Qualitative responses reveal a culture of victim-blaming and suggest that sexual abuse is likely underreported. Additionally, in slum communities, poverty may increase the pressure on adolescents, particularly females, to enter into sexual relationships in order to meet basic needs. 


\section{Programmatic Implications}

Targeted programs are needed to reach adolescents with sexual and reproductive health services at different stages of need: Adolescents in this study reported a wide range of experiences, with age, education, and marital status strongly associated with certain experiences and outcomes. There is no 'one size fits all' solution to address adolescent SRH needs; programs must consider ways to serve adolescents with comprehensive SRH information and services prior to sexual debut, as sexually active un-married adolescents, and as married individuals and couples. Attention should be paid to the wide variety of roles that adolescents play-whether students, workers, spouses or parents-in order to make SRH services accessible to this diverse population.

Strengthen sexual and reproductive health education for very young adolescents: SRH programs for adolescents often target older adolescents, missing a key opportunity to intervene prior to initiation of sexual activity. The youngest group of adolescents in our study scored very low on knowledge indicators even though they were already engaging in risky sex. Knowledge can be spread through a variety of media-school curricula, radio programs, youth groups-so it is imperative that programs identify channels that will reach this under-served population with comprehensive SRH information.

Strengthen the provision of contraceptive services for adolescents: Despite reporting generally positive attitudes towards contraceptive use, adolescents' contraceptive use (including condoms) is low and unplanned pregnancies high, indicating a need for contraceptive services, especially among unmarried adolescents. Programs should provide information and youth-friendly services for adolescents, and address the prevailing culture of stigma around adolescent sexual activity.

Poverty reduction strategies must be considered alongside sexual and reproductive health services: For adolescents living in slums, poverty constrains the ability to access quality health information and services and may also contribute to coercive sexual relationships, particularly for young women. Holistic programs that consider the relationship between health and environment are needed to address the complex web of factors that contribute to SRH. Opportunities for income generating activities among adolescents may reduce poverty, empower disenfranchised youth, and provide a forum for integration of SRH education and services. 


\section{Introduction}

\subsection{Background}

In Kenya, adolescents make up a considerable proportion of urban populations due to the high volume of young adults who migrate from rural to urban areas to look for employment. Many of them live in the numerous informal settlements which in Nairobi for example, house between 60 and $70 \%$ of the city's residents [1, 2]. Adolescents living in these slums face unique challenges as they transition to adulthood in a hostile environment characterized by high levels of unemployment, crime, poor sanitation, substance abuse, poor schooling facilities, and lack of recreational facilities [2-4]. Previous studies show that people living in informal settlements are at greater risk for HIV infection, risky sexual behavior, early childbearing, and other adverse sexual and reproductive health outcomes than those in formal settlements [2, 5-7]. In addition, they live in an environment where knowledge about contraceptive use is inadequate and access to contraceptive methods limited [6]. These challenges constitute social barriers that may impinge on their ability to have control over their sexual and reproductive life. Consequently, living in slum settlements remains a perpetual hazard to young people's development $[2,5,8]$. While much has been done to provide insights into adolescents SRH outcomes in the country, little attention has been paid to understanding and meeting the SRH challenges and needs of adolescents living in resource-poor urban settings such as informal settlements in the country. However, despite this lack of attention, the wellbeing of the urban poor, a substantial proportion of who are adolescents, will increasingly drive national development indicators, including health and poverty, in Kenya.

This report is based on secondary analysis of data collected between 2007 and 2010 under the Transition to Adulthood (TTA) project, a 3-year prospective study. The study was conducted by the African Population and Health Research Center (APHRC) among 12-24 years olds living in two informal settlements, Korogocho and Viwandani, in Nairobi, Kenya. The report highlights the SRH challenges faced by adolescents living in these slums, as well as the perceptions and strategies that adolescents adopt to deal with each of these challenges, which may have long-term effects on their health and wellbeing. The findings are expected to contribute to the design and implementation of appropriate SRH programs that respond to the unique needs of adolescent boys and girls living in poor urban settings.

\subsection{Methodology}

The TTA study investigated the inter-linkages between migration, socio-economic status, schooling and initiation of sex; risky behavior (including multiple sexual partnerships, alcohol and drug abuse), and transition to adulthood among the urban poor through a longitudinal set-up. The study identified protective and risk factors in the lives of adolescents (aged 12-24 years) growing up in Nairobi's informal settlements and examined how these factors influence adolescents' transition to adulthood. The specific aims of the study were to: a) Identify sexual and reproductive health; livelihood, education 
and other key concerns and aspirations these young people have as they grow up in urban informal settlements; b) Determine both protective and risk factors that influence adolescents' transition to secondary school, employment, independent housing, sexual and marital partnerships, parenthood as well as the sequencing of these transitions; and c) Investigate the implications of childbearing aspirations for HIVISTI prevention and vice versa, with a particular focus on dual-protection strategies.

The TTA survey was nested in the Nairobi Urban Health and Demographic Surveillance System (NUHDSS), a longitudinal platform set in 2002 by APHRC to collect and monitor health and demographic data from residents living in the Korogocho and Viwandani slums. The study commenced in 2007, with 4058 young people between the ages of 12 and 22 interviewed as part of Wave 1 from November 2007 through June 2008. In 2009 and 2010, respondents were re-interviewed in two additional waves (2,674 interviewed in Wave 2 and 1,923 interviewed in Wave 3). During the second and third waves of data collection, attempts were also made to include adolescents who were not traced in the earlier wave.

This report provides information on adolescents' background characteristics, sexual and reproductive health knowledge, SRH attitudes, sexual behavior, reproductive life and unintended pregnancies. Findings presented are based on simple descriptive statistics and cross-tabulations of indicators by age, highest level of education, schooling status and current marital status. Data presented are mainly from Wave 1. Comprehensive tables with multiple waves of data are presented in the Appendix. Analyses were performed using Stata statistical software (version 12.1) [9].

In addition, this report includes evidence based on qualitative data collected in 2009 through 75 in-depth interviews with adolescents aged 12-24 years in the two slums. Respondents for the in-depth interviews were purposively selected from participants in the baseline survey conducted in 2007-8. Respondents were selected to represent varying trajectories of experience with regard to the key markers of the transition from adolescence to adulthood which include; leaving school, getting a first job, leaving their parents' home, entering into a union, and becoming a parent. The in-depth interviews were conducted in Swahili language by trained interviewers who had previous experience working in the two slums. Interviews were conducted face-to-face in a variety of private settings depending on what was convenient for the participants. The interviews were also audio-taped. The interviews were conducted using a semi-structured interview guide developed by a team of researchers who had experience working with Kenyan adolescents. The interview guide was translated into Swahili and reviewed by bi-lingual researchers and the interviewers to ensure that meanings were not lost in translation. The interviews focused on adolescents' perceptions of what it means to be an adult, relationships with parents/guardians and any experience of pregnancy. Interviews lasted for 1 to 2 hours on average. Interviews were transcribed directly into English. Finally, for this report, a thematic analysis approach was used in which data were broadly coded into categories following the outline of the report. 


\section{Background Characteristics of Urban Poor Adolescents}

The socio-demographic characteristics of the adolescents interviewed during the first round of the survey in 2007-8 are included in Table 1. The sample was almost equally distributed between males and females. The distribution of respondents by age groups shows that $46 \%$ are aged between $15-19$ years. Most $(89 \%)$ of the adolescents had never been married. About two-thirds (68\%) of young people had a primary level of education. Over half of the adolescents were still in school at the time of the survey, with boys more likely to be in school (61\% vs. $54 \%$ ) than girls. Eight out of ten adolescents (81\%) reported living with a parent or guardian. Only $8 \%$ of young people interviewed declared that they had no religious affiliation; with boys twice as likely to report no religious affiliation as girls. Seventy-five percent of adolescents reported that they belonged to a Christian denomination, while $12 \%$ reported that they were Muslim.

Table 1. Percent distribution of women and men aged $12-22$ years by selected background characteristics

\begin{tabular}{|c|c|c|c|}
\hline \multirow{2}{*}{ Socio-demographics } & Male & Female & Total \\
\hline & $\%$ & $\%$ & $\%$ \\
\hline \multicolumn{4}{|l|}{ Age group } \\
\hline $12-14$ years & 30.3 & 29.3 & 29.8 \\
\hline $15-19$ & 46.2 & 45.4 & 45.8 \\
\hline $20-22$ & 23.5 & 25.3 & 24.4 \\
\hline \multicolumn{4}{|l|}{ Marital status } \\
\hline Never married & 96.3 & 81.7 & 89.0 \\
\hline Currently married & 3.1 & 16.2 & 9.6 \\
\hline Formerly married & 0.6 & 2.1 & 1.4 \\
\hline \multicolumn{4}{|l|}{ Education level } \\
\hline Primary or lower & 67.8 & 67.6 & 67.7 \\
\hline Secondary or higher & 32.2 & 32.3 & 32.3 \\
\hline \multicolumn{4}{|l|}{ Currently in school } \\
\hline No & 38.9 & 46.3 & 42.5 \\
\hline Yes & 61.1 & 53.7 & 57.5 \\
\hline \multicolumn{4}{|c|}{ Live with a parent/guardian } \\
\hline No & 17.4 & 20.3 & 18.8 \\
\hline Yes & 82.6 & 79.7 & 81.2 \\
\hline
\end{tabular}


Table 1. Percent distribution of women and men aged 12-22 years by selected background characteristics (Cont.)

\begin{tabular}{|l|c|c|c|}
\hline \multirow{2}{*}{ Socio-demographics } & Male & Female & Total \\
\cline { 2 - 4 } & $\%$ & $\%$ & $\%$ \\
\hline Religion & \multicolumn{3}{|c|}{} \\
\hline Catholic & 27.6 & 27.6 & 27.6 \\
\hline Protestant & 21.9 & 22.7 & 22.3 \\
\hline Pentecostal & 19.1 & 25.0 & 22.0 \\
\hline Other Christian & 3.2 & 3.1 & 3.1 \\
\hline Muslim & 12.3 & 11.2 & 11.7 \\
\hline No Religion & 11.2 & 5.3 & 8.3 \\
\hline Other & 4.6 & 5.2 & 4.9 \\
\hline N & 2048 & 2010 & 4058 \\
\hline
\end{tabular}

Source: TTA, Wave 1 data

Figure 1. Percent distribution of adolescents aged 12-22 years by living arrangements

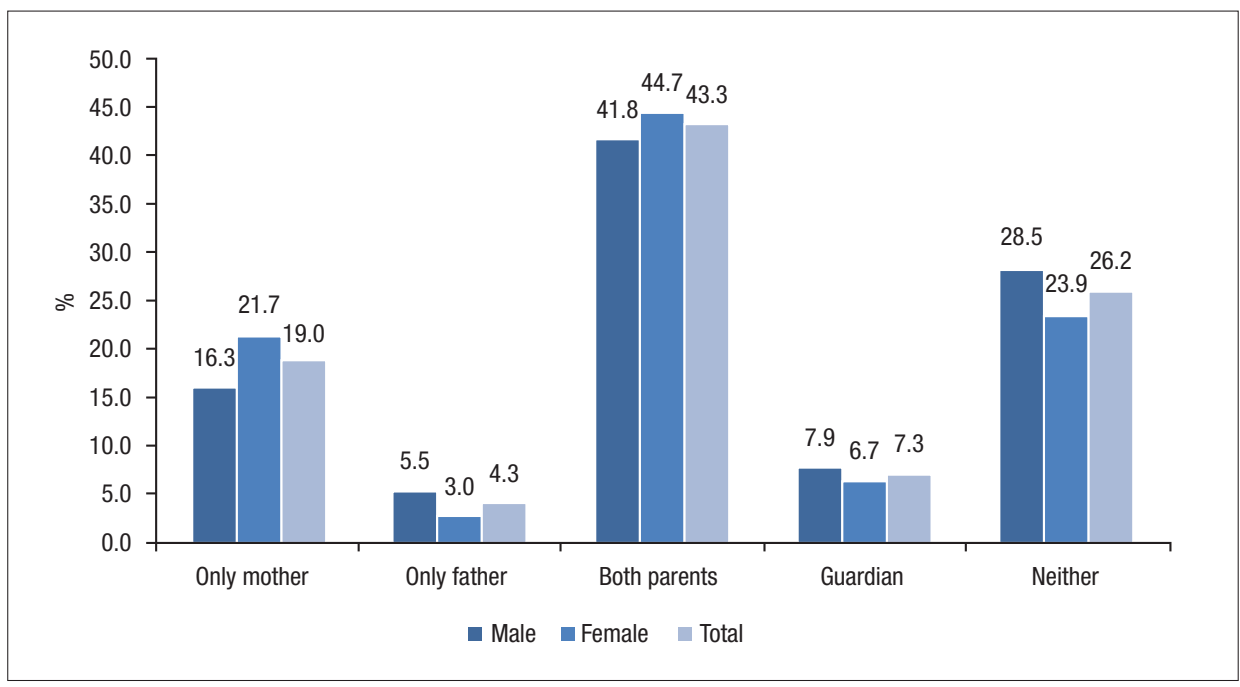

Source: TTA, Wave 2 data

About a quarter of young people indicated that they had ever worked (Table 2). Those who had worked during the month preceding the survey represented $70 \%$ of those who had ever worked and males were more likely to have worked than females. In general, these young people were involved in casual work (42\%), owned a business (30\%), or had salaried jobs (25\%). Young men were more likely to be employed in casual work than females (47\% vs. 34\%), while young females were more likely to be employed in salaried jobs (31\% vs. $22 \%$ ) or running their own businesses (34\% vs. $28 \%$ ). 
Table 2. Percent distribution of adolescents aged 12-22 years by employment status

\begin{tabular}{|c|c|c|c|}
\hline & Male & Female & Total \\
\hline & $\%$ & $\%$ & $\%$ \\
\hline \multicolumn{4}{|l|}{ Ever worked } \\
\hline No & 72.0 & 77.6 & 74.8 \\
\hline Yes & 28.0 & 22.4 & 25.2 \\
\hline $\mathrm{N}$ & 1345 & 1314 & 2659 \\
\hline \multicolumn{4}{|c|}{ Worked last month } \\
\hline No & 21.9 & 42.4 & 30.9 \\
\hline Yes & 78.1 & 57.6 & 69.1 \\
\hline $\mathrm{N}$ & 375 & 295 & 670 \\
\hline \multicolumn{4}{|l|}{ Type of work } \\
\hline Own business & 27.6 & 34.3 & 30.1 \\
\hline Casual & 47.1 & 33.7 & 42.2 \\
\hline Salaried & 21.5 & 31.4 & 25.1 \\
\hline Other & 3.8 & 0.6 & 2.6 \\
\hline $\mathrm{N}$ & 293 & 169 & 462 \\
\hline
\end{tabular}

Source: TTA, Wave 1 data

\section{Sexual and Reproductive Health Knowledge of Urban Adolescents}

\subsection{Awareness and Knowledge of the Menstrual Cycle}

An important benchmark for testing the sexual and reproductive health knowledge of adolescents, especially females, is awareness of the menstrual cycle. This is primarily because the efficacy of certain methods of birth control, such as the rhythm method, is largely based on a woman's (and her partner's) understanding of her ovulatory cycle. 
In the TTA Waves 2 and 3, adolescents were asked the question: 'From one menstrual period to the next, are there certain days when a woman is more likely to become pregnant if she has sexual intercourse?'

Overall, females were more likely than males to give a positive answer (Table 3). Data also showed that knowledge of fertile period increased with age, with older adolescents more likely to be aware of the physiology of the ovulatory cycle than younger ones. A higher proportion of out-of-school males and females ( $75 \%$ and $81 \%$, respectively) were aware of a fertile period than those currently in school. A breakdown by education level reveals that a higher proportion of both males and females with secondary or higher education were aware of the fertile period ( $79 \%$ and $82 \%$, respectively) than those with only primary level of education ( $59 \%$ and $70 \%$, respectively).

Table 3. Percent distribution of adolescents aged 12-22 years according to their knowledge of fertile period, by socio-demographic characteristics

\begin{tabular}{|l|c|c|c|c|}
\hline \multirow{2}{*}{ Age group } & \multicolumn{2}{|c|}{ Male } & \multicolumn{2}{c|}{ Female } \\
\cline { 2 - 5 } & $\%$ & N & $\%$ & N \\
\hline $12-14$ years & 40.4 & 277 & 50.6 & 249 \\
\hline $15-19$ & 66.9 & 640 & 76.2 & 623 \\
\hline $20-22$ & 77.8 & 436 & 84.0 & 449 \\
\hline Total & 65.0 & 1,353 & 74.0 & 1,321 \\
\hline Currently in school & 75.0 & 579 & 80.7 & 654 \\
\hline No & 57.4 & 761 & 67.2 & 655 \\
\hline Yes & 65.0 & 1,340 & 73.9 & 1,309 \\
\hline Total & \multicolumn{4}{|l}{} \\
\hline Education Level & 58.6 & 939 & 70.4 & 914 \\
\hline Primary or lower & 79.4 & 403 & 82.3 & 401 \\
\hline Secondary or more & 64.8 & 1,342 & 74.0 & 1,315 \\
\hline Total & \multicolumn{4}{|l}{} \\
\hline Marital status & 64.1 & 1,258 & 71.4 & 1,025 \\
\hline Never married & 74.6 & 71 & 82.4 & 250 \\
\hline Currently married & 78.3 & 23 & 87.8 & 41 \\
\hline Formerly married & 64.9 & 1,352 & 74.0 & 1,316 \\
\hline Total & 65.0 & 1,353 & 74.1 & 1,320 \\
\hline Total
\end{tabular}

Source: TTA, Wave 1 data

As a corollary to knowing that there is a fertile period, female respondents were further asked whether the time a woman was most likely to get pregnant was just before her period begins, during her period, right after her period has ended, or halfway between two periods. The results indicate that the proportion of girls aged 12 and above with adequate 
knowledge that a woman is most likely to conceive halfway between her menstrual periods was low (Table 4).

Specifically, only one in five girls between the ages of 12 and 22 accurately stated that pregnancy was most likely to occur halfway between their periods. Less than one in four girls, irrespective of whether they were currently in school or not, correctly stated that pregnancy was most likely to occur halfway between periods. Almost $40 \%$ of girls not currently in school incorrectly believed that they were most likely to conceive right after their period ended, as compared to $27 \%$ of girls currently in school. Irrespective of the level of education, about one in three girls wrongly believed that conception was most likely right after the period had ended. Surprisingly, almost one in three girls with at least secondary level education wrongly believed that conception was most likely just before her period begins. We do however note that about $26 \%$ of girls with secondary level education or higher rightly understood that pregnancy was most likely to occur halfway between two periods, compared to $19 \%$ for those with only primary level education. About a quarter of currently married girls gave the right answer, compared to $21 \%$ of never married girls and $19 \%$ of formerly married girls. With respect to living arrangements, more girls living with only their mother $(22 \%)$ correctly understood that conceiving was mostly likely halfway between periods compared to those living with their father only (16\%).

Table 4. Percent distribution of female adolescents aged 12-22 years according to their awareness of fertile period by socio-demographic characteristics

\begin{tabular}{|c|c|c|c|c|c|c|}
\hline & $\begin{array}{c}\text { Just } \\
\text { before her } \\
\text { period } \\
\text { begins }\end{array}$ & $\begin{array}{l}\text { During her } \\
\text { period }\end{array}$ & $\begin{array}{l}\text { Right after } \\
\text { her period } \\
\text { has ended }\end{array}$ & $\begin{array}{l}\text { Halfway } \\
\text { between } \\
\text { two periods }\end{array}$ & $\begin{array}{l}\text { Don't } \\
\text { know }\end{array}$ & $\mathrm{N}$ \\
\hline \multicolumn{7}{|l|}{ Age group } \\
\hline 12-14 years & 15.2 & 22.4 & 21.6 & 13.6 & 27.2 & 125 \\
\hline $15-19$ & 26.1 & 12.9 & 31.4 & 23.3 & 6.4 & 472 \\
\hline $20-22$ & 28.3 & 4.8 & 41.2 & 22.2 & 3.5 & 374 \\
\hline \multicolumn{7}{|c|}{ Currently in school } \\
\hline No & 27.9 & 7.6 & 39.4 & 21.4 & 3.6 & 523 \\
\hline Yes & 22.8 & 15.1 & 26.7 & 22.1 & 13.2 & 438 \\
\hline \multicolumn{7}{|l|}{ Education level } \\
\hline Primary or lower & 22.7 & 14.7 & 33.5 & 19.4 & 9.6 & 638 \\
\hline $\begin{array}{l}\text { Secondary or } \\
\text { higher }\end{array}$ & 30.5 & 4.0 & 34.5 & 26.2 & 4.9 & 328 \\
\hline \multicolumn{7}{|l|}{ Marital status } \\
\hline Never married & 24.0 & 13.2 & 32.5 & 20.7 & 9.6 & 726 \\
\hline Currently married & 30.2 & 4.4 & 38.5 & 24.4 & 2.4 & 205 \\
\hline Formerly married & 33.3 & 5.6 & 36.1 & 19.4 & 5.6 & 36 \\
\hline Total & 25.6 & 11.1 & 33.9 & 21.4 & 8.0 & 971 \\
\hline
\end{tabular}

Source: TTA, Wave 1 data 


\subsection{HIVIAIDS Knowledge and Testing}

A comprehensive understanding of adolescent sexual and reproductive health knowledge in the Kenyan context needs to take into consideration HIVIAIDS awareness as well as uptake of HIV counseling and testing. As adolescents transition into adulthood and begin to engage in sexual intercourse, they are at risk of HIV infection and therefore, HIVIAIDS appears to be a salient component of their sexual development.

\section{a) HIVIAIDS Knowledge}

Findings indicate that knowledge of HIVIAIDS is universal, with almost all male and female adolescents reporting that they had heard of HIVIAIDS (Table 5).

Table 5. Percentage of adolescents who have heard about HIVIAIDS, by socio-demographic characteristics

\begin{tabular}{|l|c|c|c|c|}
\hline \multirow{2}{*}{} & \multicolumn{3}{c|}{ Male } & \multicolumn{2}{c|}{ Female } \\
\cline { 2 - 5 } Age group & $\%$ & N & $\%$ & N \\
\hline $12-14$ years & 99.7 & 620 & 99.3 & 589 \\
\hline $15-19$ & 99.7 & 947 & 100 & 913 \\
\hline $20-22$ & 100 & 481 & 99.6 & 508 \\
\hline Currently in school & & & \\
\hline No & 99.9 & 791 & 99.9 & 917 \\
\hline Yes & 99.8 & 1242 & 99.6 & 1065 \\
\hline Education level & 99.9 & 1388 & 99.6 & 1360 \\
\hline Primary/lower & 99.5 & 660 & 100 & 650 \\
\hline Secondary/more & & & \\
\hline Marital status & 99.8 & 1967 & 99.7 & 1641 \\
\hline Never married & 100 & 64 & 99.7 & 325 \\
\hline Currently married & 100 & 12 & 100 & 43 \\
\hline Formerly married & 99.8 & 2043 & 99.7 & 2009 \\
\hline Total & & & & \\
\hline
\end{tabular}

Source: TTA, Wave 1 data

Qualitative interview data also shows universal awareness of HIVIAIDS. Adolescents interviewed indicated that they not only knew about HIVIAIDS but they also perceived it as a huge challenge for adolescents in the two slums. Some knew people, including other young people, who had died of AIDS. HIV infection was often associated with sexual contact. Abstinence was sometimes considered as the best way to prevent HIV infection, as seen in the quote below. 
"[My mother] advises us not to get involved in [sex] until after marriage. [Abstinence] will also help us not to get diseases like STIs and HIVIAIDS" (female, single, 16 years from Viwandani)

\section{b) HIV Counseling and Testing}

To assess uptake of HIV counseling and testing, respondents in all three waves of the TTA were asked if they had ever been tested for HIV and, if so, where they were tested and whether the test was requested, required or offered (Table 6). Males and females aged 2022 were more likely to have ever been tested, followed by those aged 15-19 years. Overall, females were more likely to have been tested than male adolescents. In addition, more adolescents who were not currently in school reported ever having been tested for HIV than those who are currently in school. Adolescents with a secondary education or higher were more likely to have ever been tested than those with primary or lower education, irrespective of gender. Currently married and formerly married girls were more than three times more likely to have been tested than never married girls. Sexually-experienced adolescents, whether male or female, were much more likely to have been tested.

Respondents were also asked the question: 'The last time you had the test, did you ask for the test, was it offered to you and you accepted or was it required?'(Table 7). More than $40 \%$ of males and females between the ages of 12-14 reported that they had asked for the test, with a similar proportion reporting that they had been offered the test and accepted. The percentage distribution of females who asked for the test dropped slightly across the other age categories.

Among males, the percentage of those asking for the test nearly doubled across the age categories from $43 \%$ for $12-14$ year-olds to $70 \%$ and $84 \%$ for $15-19$ and $20-22$ year-olds, respectively. Males who were not currently in school were twice (81\%) more likely than females (40\%) to ask for the test themselves. Adolescents of both genders with at least secondary level education were also more likely to have asked for the test themselves than their peers with only primary level education. 
Table 6. Percent distribution of adolescents who report ever been tested for HIVIAIDS, by socio-demographic characteristics

\begin{tabular}{|l|c|c|c|c|c|}
\hline \multirow{2}{*}{} & \multicolumn{3}{c|}{ Male } & \multicolumn{2}{c|}{ Female } \\
\cline { 2 - 5 } & $\%$ & N & $\%$ & N \\
\hline Age group & 4.5 & 28 & 40 & 589 \\
\hline $12-14$ years & 19.1 & 180 & 313 & 913 \\
\hline $15-19$ & 38.5 & 185 & 340 & 508 \\
\hline $20-22$ & & & & \\
\hline Currently in school & 31.5 & 249 & 546 & 917 \\
\hline No & 11.5 & 143 & 136 & 1065 \\
\hline Yes & 14.5 & 201 & 420 & 1360 \\
\hline Education level & 29.2 & 192 & 273 & 650 \\
\hline Primary or lower & & & \\
\hline Secondary or higher & 18.0 & 353 & 388 & 1641 \\
\hline Marital status & 54.7 & 35 & 271 & 325 \\
\hline Never married & 41.7 & 5 & 33 & 43 \\
\hline Currently married & 35.9 & 233 & 72.0 & 510 \\
\hline Formerly married & 11.5 & 190 & 14.1 & 183 \\
\hline Sexually experienced & & & \\
\hline Yes & & & \\
\hline No & & & \\
\hline
\end{tabular}

Source: TTA, Wave 1 data 


\begin{tabular}{|c|c|c|c|c|c|c|c|c|c|c|c|c|c|c|c|c|}
\hline & $z$ & & $\mathscr{e}$ & 守 & సิ & & $\stackrel{6}{6}$ & ש্ & & প্র & $\stackrel{\hat{N}}{\mathrm{~N}}$ & & 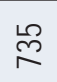 & 요 & $\infty$ & 옹 \\
\hline & 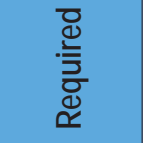 & & $\begin{array}{l}\mathscr{0} \\
\stackrel{\oplus}{\rightarrow}\end{array}$ & $\stackrel{\vec{N}}{\vec{N}}$ & 궁 & & $\begin{array}{c}\overrightarrow{-1} \\
\stackrel{\sim}{\sim}\end{array}$ & $\begin{array}{l}6 \\
\stackrel{\leftrightarrow}{\hookrightarrow}\end{array}$ & & $\begin{array}{l}\mathscr{Q} \\
\dot{v}\end{array}$ & 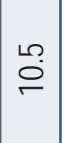 & & 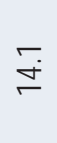 & $\stackrel{\Re}{\mathscr{\Psi}}$ & $\begin{array}{l}\text { o } \\
\text { वे }\end{array}$ & $\hat{\tilde{N}}$ \\
\hline$\overline{\bar{\alpha}}$ & 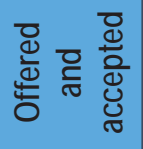 & & $\begin{array}{l}\text { o } \\
\ddot{y}\end{array}$ & $\begin{array}{l}\infty \\
\stackrel{D}{N}\end{array}$ & 공 & & $\stackrel{\sim}{\sim}$ & $\begin{array}{l}0 \\
\stackrel{N}{N}\end{array}$ & & $\stackrel{\infty}{\infty}$ & ిలి & & $\hat{\tilde{N}}$ & $\begin{array}{l}\text { N } \\
\text { N }\end{array}$ & مُ & స్ \\
\hline & 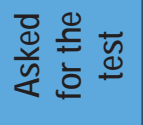 & & 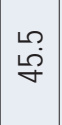 & $\begin{array}{l}\infty \\
\dot{\sim} \\
\dot{0}\end{array}$ & $\begin{array}{l}\infty \\
\dot{\forall}\end{array}$ & & 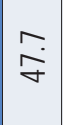 & ฮુ & & กิ่ & 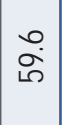 & & $\underset{\widetilde{\mho}}{\widetilde{Z}}$ & 官 & $\begin{array}{l}10 \\
0 \\
0\end{array}$ & พั่ \\
\hline & $z$ & & ळొ & ન્ & శ্ల & & $\stackrel{\bullet}{\mathscr{\forall}}$ & $\underset{\sim}{\mathbb{N}}$ & & ֻே & ঙ্ণ & & శ్రి & $\stackrel{尺}{\stackrel{0}{\sim}}$ & ల్ల & 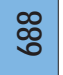 \\
\hline & 일 & & $\stackrel{\sim}{\dddot{m}}$ & $\begin{array}{l}\mathscr{N} \\
\stackrel{D}{ }\end{array}$ & 슬 & & $\begin{array}{l}O \\
\text { m }\end{array}$ & $\stackrel{\sim}{\sim}$ & & $\begin{array}{l}\text { } \\
\dot{p}\end{array}$ & $\tilde{\sigma}$ & & $\stackrel{m}{\stackrel{N}{~}}$ & 守 & m & ले \\
\hline $\begin{array}{l}\text { ह్ } \\
\text { एँ }\end{array}$ & 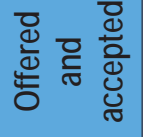 & & مٌ & $\stackrel{\stackrel{\sim}{\sim}}{\sim}$ & $\stackrel{\rightarrow}{\sim}$ & & $\stackrel{\vec{v}}{\dot{v}}$ & $\stackrel{m}{\sim}$ & & $\stackrel{\varpi}{\sim}$ & 吕 & & $\stackrel{\rightarrow}{\sim}$ & $\stackrel{\sim}{\sim}$ & $\underset{\Im}{\stackrel{-}{\Im}}$ & $\stackrel{\mathscr{0}}{\text { ผ }}$ \\
\hline & 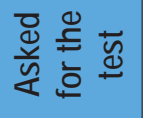 & & $\underset{⿱}{\sim}$ & $\begin{array}{l}\circ \\
\dot{q} \\
\dot{q}\end{array}$ & ָ̃ & & 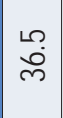 & กี & & $\begin{array}{l}\circ \\
\dot{q}\end{array}$ & 号 & & $\begin{array}{l}0 \\
\text { กิ }\end{array}$ & $\stackrel{ナ}{\stackrel{\sim}{\sim}}$ & L & テิ \\
\hline & $z$ & & $\stackrel{\sim}{\sim}$ & $\underset{\sim}{\stackrel{\infty}{\rightarrow-1}}$ & ஜ્ન & & ઠి & ન્ન & & $\underset{\sim}{\stackrel{\sim}{\sim}}$ & $\stackrel{\mathscr{্}}{\underset{ᄀ}{+}}$ & & 窊 & $\stackrel{\text { L }}{\text { n }}$ & م & శ్లి \\
\hline & 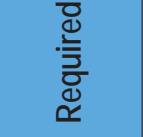 & & 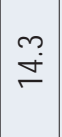 & $\stackrel{N}{N}$ & "ִ חָ & & $\stackrel{\sim}{\circ}$ & $\underset{\sim}{\sim}$ & & $\stackrel{\llcorner}{\forall}$ & $\underset{\exists}{\exists}$ & & $\stackrel{ナ}{\sim}$ & $\stackrel{\overbrace{}}{\sim}$ & 웅 & જ્ \\
\hline$\frac{\frac{\omega}{\sigma}}{\Sigma}$ & 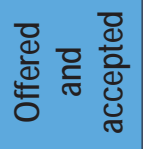 & & $\stackrel{\overbrace{}}{\Im}$ & $\begin{array}{l}\infty \\
\mathbb{N}\end{array}$ & ᄋ̊ & & 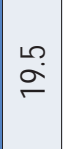 & $\begin{array}{l}\infty \\
\\
\end{array}$ & & 임 & $\stackrel{\llcorner}{\sim}$ & & $\stackrel{\circ}{\stackrel{\leftrightarrow}{-}}$ & $\begin{array}{l}0 \\
\infty\end{array}$ & 우 & 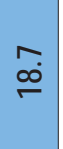 \\
\hline & 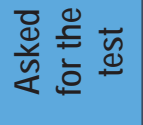 & & $\begin{array}{l}\stackrel{\overbrace{}}{\sharp} \\
\stackrel{f}{*}\end{array}$ & 움 & ஜு & & $\stackrel{\circ}{i}$ & $\begin{array}{l}\circ \\
\infty \\
\infty\end{array}$ & & $\begin{array}{l}6 \\
\dot{8}\end{array}$ & $\begin{array}{l}\text { m } \\
\tilde{\sigma}\end{array}$ & & $\stackrel{\bullet}{\mathbb{N}}$ & $\begin{array}{l}0 \\
\infty \\
\infty \\
\infty\end{array}$ & 옴 & 过 \\
\hline & & $\begin{array}{l}\text { 을 } \\
\text { 읗 } \\
\text { gั } \\
\frac{5}{4}\end{array}$ & 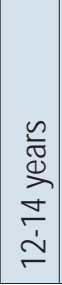 & 官 & 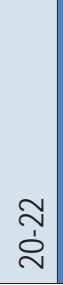 & 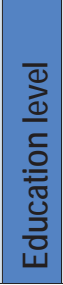 & 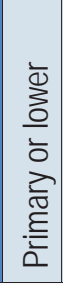 & 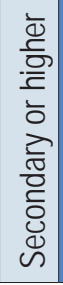 & 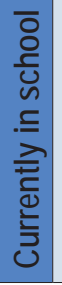 & 울 & $\stackrel{\mathscr{L}}{\rightleftharpoons}$ & 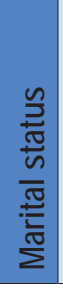 & 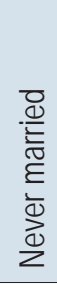 & 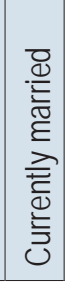 & 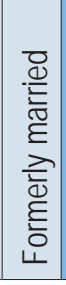 & 퓽 \\
\hline
\end{tabular}


Eighty-nine percent of currently married males reported having asked for the test themselves, while among females, only $27 \%$ of currently married females reported they had asked for the test. Almost $73 \%$ of never married boys and $53 \%$ of never married girls reported asking for the test themselves.

About half of all males reported that they received their most recent HIV test in a voluntary counseling and testing (VCT) center (Table 8). Irrespective of background, about one in five males reported using a government clinic or hospital. By education level, males with secondary or more education and those not currently in school were more likely to have been tested at a VCT center.

Overall, females relied less on VCT centers and more on government clinics and private hospitals than their male counterparts. There were no significant differences by background characteristics in use of private clinics or NGO clinics. As with the males, a higher proportion of females with secondary or more education had their most recent test at a VCT center. 


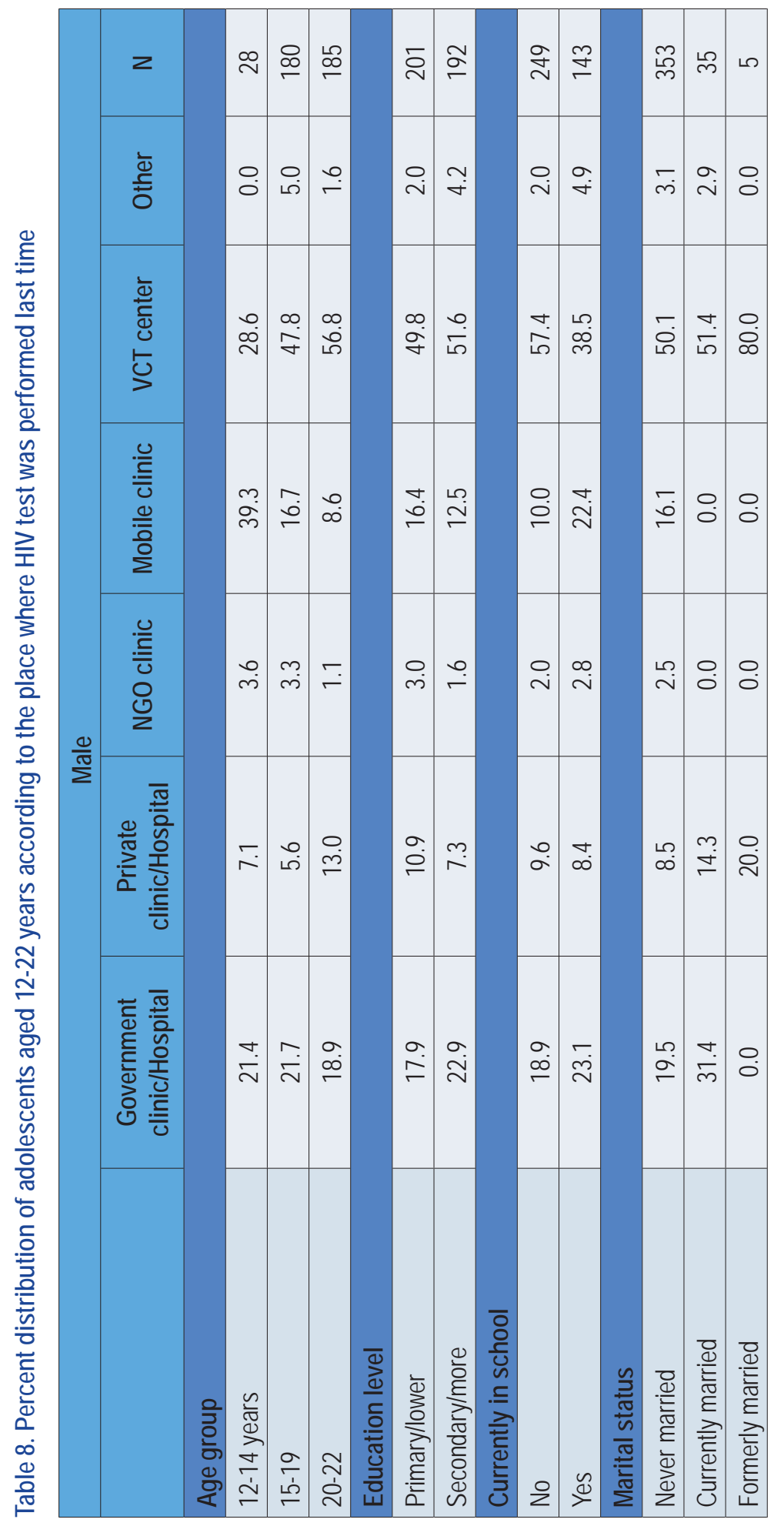




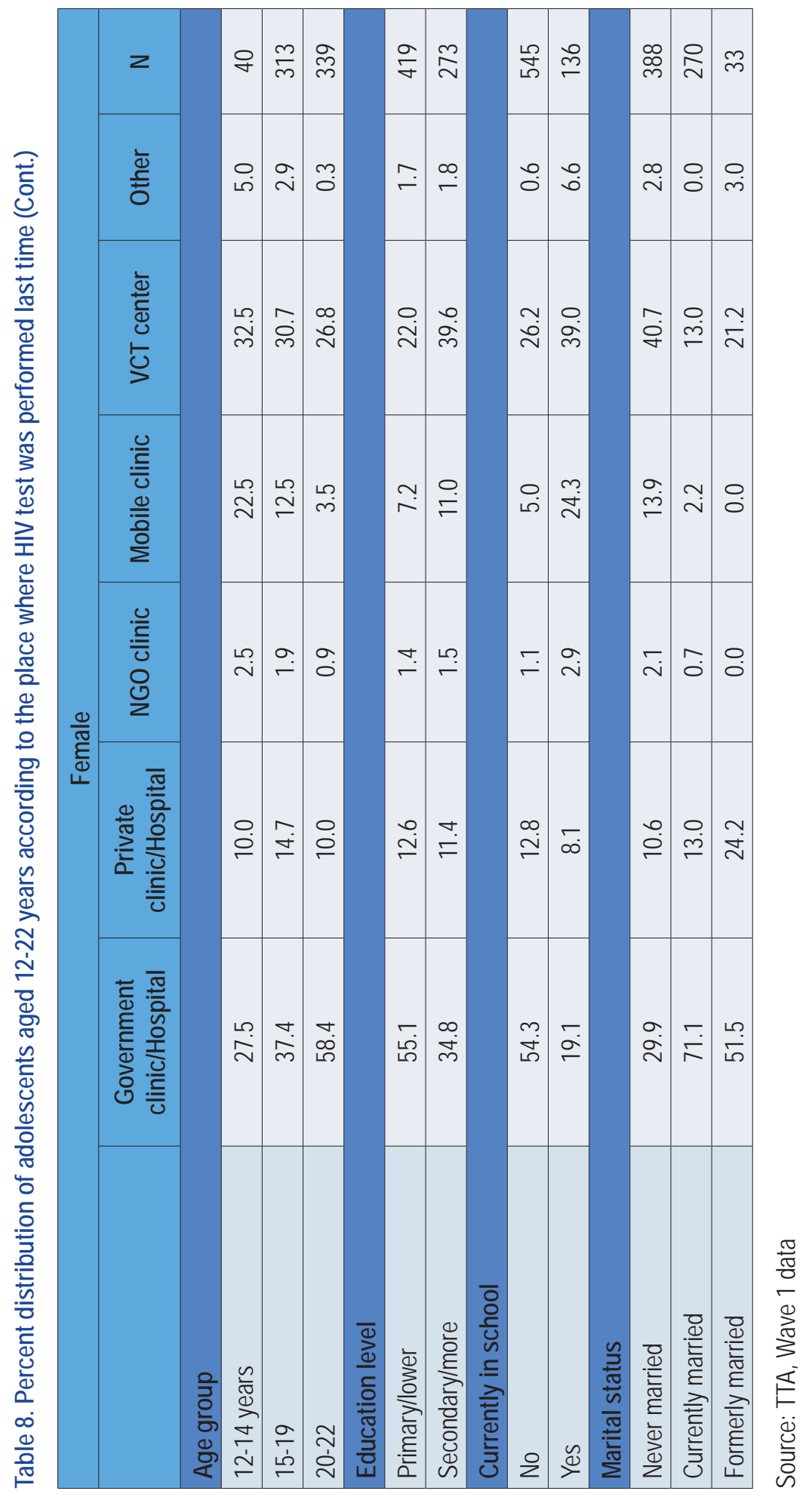


During the survey, young people were asked to give the main reason why they had or had not been tested for HIV (Table 9). Both males and females indicated that their top reason for getting tested was to know their status; a response that accounted for $52 \%$ of males and $35 \%$ of females that had been tested. The wide gender difference in getting tested is explained by the large proportion of females who were tested for HIV during pregnancy; a reason given by one out of every three females. It is interesting to note that $40 \%$ of males and $24 \%$ of females were tested for HIV because their partners told them to get tested. This suggests that partner communication about HIV plays an important role in the decision to get tested.

We found among respondents several reasons for not getting tested for HIV (Table 9) and top on that list was not being sexually active. This was true for both males and females. One in three adolescents did not get tested because they perceived that they were not at risk of HIV for reasons other than abstinence although their perception of risk may not reflect actual risk. Less than $10 \%$ of the adolescents simply did not want to know their status. An even smaller proportion (less than $5 \%$ ) had not been tested because they did not know where to go for testing, while a few of them cited cost as a barrier to getting tested for HIV.

Table 9. Reasons for testing or not testing for HIV among adolescents aged 12-22 years, by gender

\begin{tabular}{|l|c|c|c|}
\hline Reason for getting tested for HIV & Male & Female & Both \\
\hline To know status & 52.1 & 34.7 & 42.0 \\
\hline Pregnant/Prenatal visit & 0.2 & 33.9 & 19.8 \\
\hline "I'm sexually active" & 0.2 & 0.4 & 0.3 \\
\hline Encouraged by counselor & 0.8 & 1.8 & 1.4 \\
\hline Encouraged by peer educator & 1.1 & 0.9 & 1.0 \\
\hline Encouraged by peers & 1.1 & 0.6 & 0.8 \\
\hline To get married & 0.3 & 0.0 & 0.1 \\
\hline Partner told me to & 40.1 & 24.0 & 30.7 \\
\hline Concern about a partner & 0.2 & 0.2 & 0.2 \\
\hline Required to get a job & 0.5 & 0.1 & 0.3 \\
\hline Other & 3.2 & 3.1 & 3.2 \\
\hline Total & 649 & 900 & 1549 \\
\hline Reason for not getting tested for HIV & Male & Female & Both \\
\hline Not sexually active & 34.6 & 39.7 & 36.8 \\
\hline Not at risk for other reasons & 33.5 & 34.9 & 34.1 \\
\hline Do not know where & 4.4 & 4.6 & 4.5 \\
\hline Costs too much & 0.3 & 0.3 & 0.3 \\
\hline Can get infected & 0.5 & 0.8 & 0.6 \\
\hline
\end{tabular}


Table 9. Reasons for testing or not testing for HIV among adolescents aged 12-22 years, by gender (Cont.)

\begin{tabular}{|l|c|c|c|}
\hline Reason for not getting tested for HIV & Male & Female & Both \\
\hline Don't want to know & 9.1 & 6.3 & 7.8 \\
\hline Someone might see & 1.0 & 0.5 & 0.8 \\
\hline Other & 16.7 & 13.0 & 15.0 \\
\hline Total & 1481 & 1185 & 2666 \\
\hline
\end{tabular}

Source: TTA, Wave 1 data

\section{Urban Adolescents' SRH Attitudes}

\subsection{Attitudes towards Sex and Contraception}

Attitudes toward sex and conception were measured in the TTA data using a series of questions. Adolescents were asked to 'agree or disagree' to the following statements about sex: 'Young women should remain virgins until they marry,' 'young men should remain virgins until they marry,' and 'usually people do not plan to have sex, it just happens.' Results on attitudes toward sex and contraception are captured in Table 10 and are disaggregated by age categories.

The majority of males and females adolescents irrespective of age reported that young women should remain virgins till marriage. When the same question was asked about young men, we saw similar responses with $82 \%$ of males and $87 \%$ of females believing that young men should remain virgins until marriage. We noted though that this belief decreased as age increased.

When adolescents were asked if they agreed that 'people usually do not plan to have sex, it just happens,' a majority of both males and females responded with a 'no.' Interestingly, the difference between those who thought sex 'just happens' and those who disagreed among adolescents ages 20-22 was not very big. In fact, almost 1 in 2 adolescents (male and female) believed sex just happens; therefore, people do not plan for it.

With regards to attitudes towards contraceptive use, adolescents were asked to state if they agreed or disagreed with the following statements: 'It is smart to use birth control to prevent an unplanned pregnancy' and 'it's a good idea to use condoms to protect against getting HIVIAIDS'. The majority of both boys and girls agreed that it was smart to use contraceptives to prevent unplanned pregnancies, with support increasing with age for both genders. An equally high percentage of adolescents agreed that it is a 'good idea to use condoms as a way to prevent being infected by HIVIAIDS,' and agreement increased with age for both males and females. To assess perceptions about the ease of obtaining contraceptives, the question 'do you agree or disagree that it is difficult for young people to obtain birth control/contraceptives' was asked. Over $70 \%$ of adolescents (both boys and girls) disagreed, implying that they believe obtaining birth control or contraceptives is not a difficult task for adolescents. 
Table 10. Percent distribution of adolescents aged $12-22$ years according to their attitudes towards sex and contraception

\begin{tabular}{|c|c|c|c|c|c|c|c|c|}
\hline \multicolumn{9}{|c|}{ Attitudes towards sex and contraception } \\
\hline \multicolumn{5}{|c|}{ Male } & \multicolumn{4}{|c|}{ Female } \\
\hline & $12-14$ & $15-19$ & $20-22$ & Total & $12-14$ & 15-19 & $20-22$ & Total \\
\hline \multicolumn{9}{|c|}{ Young women should remain virgins until marriage } \\
\hline No & 9.0 & 12.6 & 15.6 & 12.2 & 5.8 & 8.3 & 14.8 & 9.2 \\
\hline Yes & 91 & 87.4 & 84.4 & 87.8 & 94.2 & 91.7 & 85.2 & 90.8 \\
\hline \multicolumn{9}{|c|}{ Young men should remain virgins until marriage } \\
\hline No & 11.1 & 19.0 & 25.4 & 18.1 & 7.6 & 13.3 & 19.3 & 13.1 \\
\hline Yes & 88.9 & 81.0 & 74.6 & 81.9 & 92.4 & 86.7 & 80.7 & 86.9 \\
\hline \multicolumn{9}{|c|}{ Sex just happens } \\
\hline No & 69.8 & 52.7 & 49.7 & 57.2 & 70.8 & 55.3 & 49.8 & 58.5 \\
\hline Yes & 30.2 & 47.3 & 50.3 & 42.8 & 29.2 & 44.7 & 50.2 & 41.5 \\
\hline \multicolumn{9}{|c|}{ Smart to use contraception to prevent unplanned pregnancies } \\
\hline No & 25.0 & 14.6 & 10.0 & 16.7 & 18.7 & 11.5 & 6.1 & 12.2 \\
\hline Yes & 75.0 & 85.4 & 90.0 & 83.3 & 81.3 & 88.5 & 93.9 & 87.8 \\
\hline \multicolumn{9}{|c|}{ Good idea use condom to prevent HIVIAIDS } \\
\hline No & 16.6 & 14.1 & 12.1 & 14.4 & 23.3 & 17.3 & 12.8 & 17.9 \\
\hline Yes & 83.4 & 85.9 & 87.9 & 85.6 & 76.7 & 82.7 & 87.2 & 82.1 \\
\hline \multicolumn{9}{|c|}{ Difficult to obtain contraceptives } \\
\hline No & 73.9 & 73.7 & 73.4 & 73.7 & 73.7 & 73.8 & 75.4 & 74.2 \\
\hline Yes & 26.1 & 26.3 & 26.6 & 26.3 & 26.3 & 26.2 & 24.6 & 25.8 \\
\hline $\mathrm{N}$ & 620 & 946 & 481 & 2047 & 589 & 913 & 508 & 2010 \\
\hline
\end{tabular}

Source: TTA, Wave 1 data

Qualitative interviews reveal similar patterns with regards to attitudes towards contraception and condom use. Most respondents were of the view that abstinence was the best way to avoid pregnancy, STIS and HIVIAIDS. However, in cases where abstinence was not attainable, they were of the view that it was smart to use contraceptives to prevent pregnancy. In a few interviews, such as the one with a female in Viwandani presented below, it was implicitly suggested that abortion was applied as a method of contraception.

Respondent: "...It is just about sex, some people just have sex for fun, they don't know what it means and again, early marriage, having babies at the wrong time, I mean when they are still too young..."

Interviewer: "What are some of the strategies that young people in this neighborhood use to cope with these challenges?" 
Respondent: "Some abstain, others use contraception...some do abortions" (Female, separated, 20 years)

There were, however, notable misconceptions expressed by the respondents, which often had a negative impact on adolescents' understanding and attitudes towards contraception. This is well exemplified in an interview with a young woman from Viwandani:

"There are some girls who are involved in sexual activities and use contraceptives like birth control pills; we are advised that if we start using those pills early in life, they will make us barren in future. We are also told at school that the use of condoms is not good because there are some chemicals used in their manufacture and constant use of them can affect you in one way or another." (Female, single, 16 years)

\subsection{Intention to Use Contraception in the Future}

Adolescents were asked if they think they will use a contraceptive method to delay or avoid pregnancy at any time in the future. Findings in Table 11 indicate that $45 \%$ of males and $52 \%$ of females intend to use a contraception method in the future. A sizeable proportion of adolescents did not know whether they would use contraceptives in the future, though this was heavily influenced by the uncertainty of the youngest age group. Education was associated with future intention of using contraceptives for both genders, with those having secondary level of education reporting that they would want to use contraception in the future compared to $40 \%$ of males and $48 \%$ of females with primary education or lower. A greater proportion of adolescents who were out of school reported that they intended to use contraceptives in the future compared to those in school $(55 \%$ vs. $39 \%$ for males and $67 \%$ vs. $40 \%$ for females). Currently married and formerly married adolescents were more likely to report future intention to use contraceptives than their unmarried counterparts. Unmarried adolescents were also several times more likely to be unsure of future contraception use.

Table 11. Percent distribution of adolescents aged 12-22 years according to their intention to use contraception in the future, by socio-demographic characteristics

\begin{tabular}{|c|c|c|c|c|c|c|c|c|}
\hline & \multicolumn{4}{|c|}{ Male } & \multicolumn{4}{|c|}{ Female } \\
\hline & Yes & No & $\begin{array}{l}\text { Don't } \\
\text { know }\end{array}$ & $\mathrm{N}$ & Yes & No & $\begin{array}{l}\text { Don't } \\
\text { know }\end{array}$ & $\mathrm{N}$ \\
\hline \multicolumn{9}{|l|}{ Age group } \\
\hline $12-14$ years & 29.3 & 29.0 & 41.7 & 618 & 31.8 & 26.2 & 42 & 588 \\
\hline $15-19$ & 48.8 & 35.9 & 15.3 & 945 & 54.3 & 31.5 & 14.3 & 912 \\
\hline $20-22$ & 60.0 & 29.0 & 11.0 & 480 & 72.3 & 20.9 & 6.7 & 506 \\
\hline \multicolumn{9}{|l|}{ Education level } \\
\hline Primary or higher & 40.0 & 33.2 & 26.8 & 1385 & 48.1 & 27.5 & 24.4 & 1358 \\
\hline Secondary or higher & 57.1 & 29.9 & 12.9 & 658 & 61 & 26.9 & 12.2 & 648 \\
\hline
\end{tabular}


Table 11. Percent distribution of adolescents aged 12-22 years according to their intention to use contraception in the future, by socio-demographic characteristics (Cont.)

\begin{tabular}{|l|c|c|c|c|c|c|c|c|c|}
\hline \multirow{2}{*}{} & \multicolumn{7}{|c|}{ Male } & \multicolumn{5}{c|}{ Female } \\
\cline { 2 - 10 } & Yes & No $\begin{array}{l}\text { Don't } \\
\text { know }\end{array}$ & N & Yes & No & $\begin{array}{l}\text { Don't } \\
\text { know }\end{array}$ & N \\
\hline Currently in school & 55.3 & 31.9 & 12.8 & 790 & 66.8 & 24.8 & 8.3 & 914 \\
\hline No & 39.4 & 32.3 & 28.3 & 1239 & 39.9 & 28.7 & 31.4 & 1064 \\
\hline Yes & 44.7 & 32.3 & 23.0 & 1963 & 47 & 28.6 & 24.4 & 1637 \\
\hline Marital status & 65.6 & 31.3 & 3.1 & 64 & 75.1 & 22.2 & 2.8 & 325 \\
\hline Never married & 66.7 & 25.0 & 8.3 & 12 & 79.1 & 16.3 & 4.7 & 43 \\
\hline Currently married & 45.5 & 32.2 & 22.3 & 2039 & 52.2 & 27.3 & 20.5 & 2005 \\
\hline Formerly married & & & & & \\
\hline Total & & & & & \\
\hline
\end{tabular}

Source: TTA, Wave 1 data

\subsection{Attitudes towards Family}

Majority of females and males believe that it is important to have children (Table 12). Disaggregation by socio-demographic background reveals little differences. A person with at least secondary education or an individual currently in school was just as likely to think 'it is very important to have children' as someone with primary or lower education or someone not currently in school.

Table 12. Percentage of adolescents according to their attitudes towards family, by sociodemographic characteristics

\begin{tabular}{|c|c|c|c|c|c|c|}
\hline \multicolumn{7}{|c|}{ Percentage of adolescents who think it is very important to have children } \\
\hline & \multicolumn{3}{|c|}{ Male } & \multicolumn{3}{|c|}{ Female } \\
\hline & No & Yes & $\mathrm{N}$ & No & Yes & N \\
\hline \multicolumn{7}{|l|}{ Age group } \\
\hline $12-14$ years & 15.3 & 84.7 & 620 & 21.6 & 78.4 & 587 \\
\hline $15-19$ & 12.2 & 87.8 & 944 & 13.8 & 86.2 & 875 \\
\hline $20-22$ & 6.3 & 93.7 & 473 & 8.8 & 91.2 & 464 \\
\hline \multicolumn{7}{|l|}{ Education level } \\
\hline Primary/lower & 12.7 & 87.3 & 1382 & 15.9 & 84.1 & 1294 \\
\hline Secondary/more & 9.8 & 90.2 & 655 & 13.1 & 86.9 & 632 \\
\hline \multicolumn{7}{|c|}{ Currently in school } \\
\hline No & 10.1 & 89.9 & 781 & 9.8 & 90.2 & 838 \\
\hline Yes & 12.6 & 87.4 & 1242 & 19.4 & 80.6 & 1064 \\
\hline
\end{tabular}


Table 12. Percentage of adolescents according to their attitudes towards family, by sociodemographic characteristics (Cont.)

\begin{tabular}{|c|c|c|c|c|c|c|}
\hline \multicolumn{7}{|c|}{ Percentage of adolescents who think it is very important to have children } \\
\hline & \multicolumn{3}{|c|}{ Male } & \multicolumn{3}{|c|}{ Female } \\
\hline & No & Yes & $\mathbf{N}$ & No & Yes & $\mathbf{N}$ \\
\hline \multicolumn{7}{|l|}{ Marital status } \\
\hline Never married & 11.9 & 88.1 & 1962 & 16.6 & 83.4 & 1622 \\
\hline Currently married & 8.5 & 91.5 & 59 & 5.6 & 94.4 & 270 \\
\hline Formerly married & 8.3 & 91.7 & 12 & 14.7 & 85.3 & 34 \\
\hline Total & 11.8 & 88.2 & 2033 & 15.0 & 85.0 & 1926 \\
\hline \multicolumn{7}{|c|}{ Percentage of adolescents who think it is very important to get married } \\
\hline & \multicolumn{3}{|c|}{ Male } & \multicolumn{3}{|c|}{ Female } \\
\hline & No & Yes & $\mathbf{N}$ & No & Yes & $\mathbf{N}$ \\
\hline \multicolumn{7}{|l|}{ Age group } \\
\hline 12-14 years & 18.1 & 81.9 & 620 & 24.1 & 75.9 & 585 \\
\hline $15-19$ & 14.3 & 85.7 & 941 & 19.4 & 80.6 & 869 \\
\hline $20-22$ & 7.7 & 92.3 & 468 & 14.4 & 85.6 & 445 \\
\hline \multicolumn{7}{|l|}{ Education level } \\
\hline Primary/lower & 15.1 & 84.9 & 1379 & 20.0 & 80.0 & 1275 \\
\hline Secondary/more & 11.5 & 88.5 & 650 & 19.1 & 80.9 & 624 \\
\hline \multicolumn{7}{|c|}{ Currently in school } \\
\hline No & 11.0 & 89.0 & 775 & 15.6 & 84.4 & 818 \\
\hline Yes & 15.6 & 84.4 & 1241 & 22.9 & 77.1 & 1059 \\
\hline \multicolumn{7}{|l|}{ Marital status } \\
\hline Never married & 14.2 & 85.8 & 1962 & 21.3 & 78.7 & 1628 \\
\hline Currently married & 5.7 & 94.3 & 53 & 6.5 & 93.5 & 231 \\
\hline Formerly married & 10.0 & 90.0 & 10 & 32.5 & 67.5 & 40 \\
\hline Total & 14.0 & 86.0 & 2025 & 19.7 & 80.3 & 1899 \\
\hline
\end{tabular}

Source: TTA, Wave 1 data

Table 12 also presents adolescents' attitudes towards marriage. Adolescents were asked if they believed that 'it is very important to get married.' Over $80 \%$ of both males and females responded that getting married was very important. The differences across sociodemographic characteristics were negligible. It is interesting to note that $21 \%$ of never married and 33\% of formerly married females did not think marriage was 'very important.'

Similar results are seen in the in-depth interviews, in which most adolescents, male and female, agreed on the importance of marriage. Reasons for marriage ranged from the 
need to conform to tradition and fulfill social responsibilities to the need to procreate and extend their family lineage, as seen in the quotes below:

"Reasons for getting married are of course so that I can also start a family like my sister. [I want to start to have sex] when I am married because I have to keep our generation tree on course" (Female, single, 21 years)

"I don't want to remain a spinster but would also like to enjoy life the way my mother did. I want bride price to be paid" (Female, single, 16 years)

As much as there was general consensus about the importance of marriage, there was great variation in regard to the ideal age at which to get married. Most respondents agreed that the ideal age to marry was above 18 years, which is in line with the legal definition of adulthood and acceptable age of marriage in Kenya, but could not agree on the exact age at which marriage is ideal.

Many respondents tended to pin the ideal age of marriage to maturity, which translated to a variety of meanings, including economic independence, completion of education and the ability of one to raise a family. The quotes below illustrate these sentiments:

"I have never planned to get married this soon. I want to get married after I have achieved my goals [which are; to] finish college and get a job, then I can think of marriage." (Female, single, 23 years)

"After completing school, in employment and living on my own, then I can think of marriage ...At the age of 25 ...I will be mature then." (Female, single, 17 years)

"[I would like to be married] when I attain 27 years because by then I will be mature, both physically and mentally in decision making." (Female, single, 21 years)

\section{Sexual Behavior among Adolescents}

Sexual activity exposes adolescents to risks of early or unintended pregnancies, induced abortions, infant and maternal morbidity and mortality, and sexually transmitted infections (STIS) such as HIVIAIDS. For example, adolescents' early sexual acts are often not protected, and thus early sexual debut can have adverse effects through exposure to unintended pregnancies and STIs. In this section, we look at sexual initiation, circumstances of sexual debut, and recent sexual activity among adolescents interviewed in the two slums.

\subsection{Initiation of Sexual Activity}

Over $30 \%$ of the boys and girls were sexually experienced (Table 13). However, older adolescents were more likely to have engaged in sexual intercourse than younger adolescents (12-14 years). The percentage of adolescents who had engaged in sexual intercourse was higher among those with secondary education than those with primary or a lower level of education, though this might be in part a reflection of the fact that the youngest age group mainly had a primary level of education. 
Findings also showed that both male and female adolescents who were still in school were less likely to have engaged in sex than their counterparts who were no longer in school. As would be expected, almost all married adolescents had engaged in sexual intercourse.

Table 13. Percentage of adolescents who have initiated sex, by socio-demographic characteristics

\begin{tabular}{|c|c|c|c|c|c|c|c|c|}
\hline & \multicolumn{4}{|c|}{$\%$ of ever had sex } & \multicolumn{4}{|c|}{$\begin{array}{c}\% \text { of those who initiated sex } \\
\text { before age } 15\end{array}$} \\
\hline & Male & $\mathbf{N}$ & Female & $\mathbf{N}$ & Male & $\mathrm{N}$ & Female & $\mathrm{N}$ \\
\hline \multicolumn{9}{|l|}{ Age group } \\
\hline 12-14 years & 3.4 & 620 & 3.4 & 589 & 3.2 & 620 & 3.6 & 589 \\
\hline $15-19$ & 31.4 & 947 & 33.3 & 913 & 11.9 & 947 & 9.3 & 913 \\
\hline $20-22$ & 68.8 & 481 & 75.8 & 508 & 19.3 & 481 & 9.1 & 508 \\
\hline \multicolumn{9}{|l|}{ Education level } \\
\hline Primary or lower & 26.0 & 1388 & 33.8 & 1360 & 9.7 & 1388 & 8.4 & 1360 \\
\hline Secondary or higher & 43.6 & 660 & 38.5 & 650 & 13.8 & 660 & 5.8 & 650 \\
\hline \multicolumn{9}{|l|}{ Currently in school } \\
\hline No & 60.3 & 791 & 67.1 & 917 & 18.7 & 791 & 12.9 & 917 \\
\hline Yes & 13.4 & 1242 & 7.4 & 1065 & 6.2 & 1242 & 2.4 & 1065 \\
\hline \multicolumn{9}{|l|}{ Marital status } \\
\hline Never married & 29.1 & 1967 & 21.1 & 1641 & 10.4 & 1967 & 5.5 & 1641 \\
\hline Currently married & 100.0 & 64 & 98.8 & 325 & 21.9 & 64 & 15.7 & 325 \\
\hline Formerly married & 100.0 & 12 & 95.3 & 43 & 41.7 & 12 & 25.6 & 43 \\
\hline Total & 31.7 & 2043 & 35.2 & 2009 & 11.0 & 2043 & 7.6 & 2009 \\
\hline
\end{tabular}

Source: TTA, Wave 1 data

Table 13 also shows the prevalence of early sexual debut among adolescents living in the two slums. Early sexual debut is defined as sexual experience before age 15 . About $11 \%$ of males and $8 \%$ of females reported sexual intercourse for the first time before the age of 15 . Being out of school was associated with early sexual debut for both genders. About three times as many males who were no longer in school at the time of survey had initiated sex before the age 15 as compared to those who were still in school. For females, only $2 \%$ of girls still in school reported experiencing early sexual debut compared to $13 \%$ of their counterparts who were out of school.

In-depth interview accounts indicate that for the majority of adolescents who had initiated sex at any age, their first sexual experience was consensual. Most female respondents cited love as the reason they first had sex with their partners. Male accounts of their first sexual encounter differed with the overriding reasons for them being curiosity, opportunity and discovery. 
The excerpts below illustrate the contrast between females and males:

"We were in love." (Female, single, 19 years)

"He used to sweet-talk me, we were in a relationship and both loved each other." (Female, separated, 20 years)

"Yes, I had sex at the age of 16 years and the man was older than me. He was 20 years by then, even though we separated, he still insists on us having sex but I don't want to continue with that. I had the first sex with him because I loved him." (Female, single, 22 years)

"It was more of curiosity than enjoyment because when you sit with others, you hear of stories about their sexual behavior and you become curious and tries it out on the first opportunity you get." (Male, single, 22 years)

"I had just discovered there are such feelings and was trying them out. I don't think I can even tell you what it really was because I didn't feel anything, even the girl I don't think she felt anything... I was 14." (Male, single, 22 years)

"We were on discovery mission" (Male, single, 23 years)

The in-depth interviews also sought to find out whether adolescents used protection during their first sexual encounter and reasons for not using any protection. Adolescents, especially females, overwhelmingly reported that they did not use any protection or contraceptives during their first sexual encounter. The most cited reason for not using protection or contraceptives was lack of knowledge. Other reasons cited for non-use of protection during the first sexual encounter were love or trust and being in a marital union. The aspect of trust was distinctively associated with the perception that the couples were young, and therefore they did not suspect that, at that age, their partner had experienced sexual relations with other partners that put them at risk of contracting STIs. The following illustrate the role of trust:

"... I didn't suspect she would be infected or anything" (Male, single, 16 years)

"... I trusted her, both of us were innocent" (Male, single, 22 years)

"...We were married and didn't see the need" (Female, married, 21 years)

\subsection{Recent Sexual Activity}

About a fifth of the boys and a quarter of the girls reported recent sexual activity (Table 14). As expected, older adolescents were more likely to report sexual intercourse over the past 12 months with half of male adolescents aged 20-22 (48\%) and almost two-thirds of females of the same age (63\%) reporting recent sexual intercourse. Reported recent sexual activity was lower (less than 30\%) among adolescents' boys and girls aged 15-19 years. A larger proportion of adolescents with secondary level of education reported recent sexual activity compared to those with primary or lower education. 
However, a much lower proportion of in-school adolescents than out-of-school adolescents reported recent sexual activity. As expected, married adolescents were much more likely to report recent sexual activity than their non-married counterparts.

Table 14. Percentage of adolescents aged 12-22 years who had a sexual encounter over the 12 months preceding the survey, by socio-demographic characteristics

\begin{tabular}{|c|c|c|c|c|}
\hline & Male & $\mathrm{N}$ & Female & $\mathrm{N}$ \\
\hline \multicolumn{5}{|l|}{ Age group } \\
\hline $12-14$ years & 0.6 & 620 & 1.7 & 589 \\
\hline $15-19$ & 19.5 & 947 & 26.4 & 913 \\
\hline $20-22$ & 47.8 & 481 & 63.0 & 508 \\
\hline \multicolumn{5}{|l|}{ Education level } \\
\hline Primary or lower & 16.6 & 1388 & 27.3 & 1360 \\
\hline Secondary or higher & 28.6 & 660 & 30.8 & 650 \\
\hline \multicolumn{5}{|l|}{ Currently in school } \\
\hline No & 41.5 & 791 & 55.4 & 917 \\
\hline Yes & 7.0 & 1242 & 4.9 & 1065 \\
\hline \multicolumn{5}{|l|}{ Marital status } \\
\hline Never married & 17.8 & 1967 & 14.7 & 1641 \\
\hline Currently married & 90.6 & 64 & 93.5 & 325 \\
\hline Formerly married & 75.0 & 12 & 60.5 & 43 \\
\hline Total & 20.5 & 2043 & 28.4 & 2009 \\
\hline
\end{tabular}

Source: TTA, Wave 1 data

The majority of sexually active adolescents had only one partner; $67 \%$ for boys and $94 \%$ for girls. Adolescent girls reported having fewer sexual partners over the past 12 months than their male counterparts (Table 15).

Our findings also show that the proportion of adolescent males reporting at least two sexual partners decreases with age, going from $50 \%$ for $12-14$ year-olds to $35 \%$ for $15-19$ year-olds and 33\% for 20-22 year-olds. Similarly, the percentage of adolescent females reporting multiple partners goes down from $30 \%$ for $12-14$ year-olds to $8 \%$ and $4 \%$ for 15 19 and 20-22 year-olds, respectively. However, the sample size of 12-14 year-olds who had experienced sex is extremely small compared to the other age categories, making it difficult to draw conclusions about this age group. Additionally, these adolescents are already outliers because of their early sexual debut, and it may be that adolescents who initiate sex early are also more likely to have more than one partner in a year.

For both genders, there was little difference in the number of partners based on education level. In addition, it is striking that females who were still in school were three times more likely to have multiple partners than their counterparts who were no longer in school. 
Perhaps, the in-school girls who have initiated sex are a selected group whose specific characteristics predispose them to a higher likelihood of risky sexual behavior such as having multiple partners. For boys, there was no significant difference by schooling status.

Table 15. Percent distribution of adolescents according to the number of sexual partners over the last 12 months, by socio-demographic characteristics

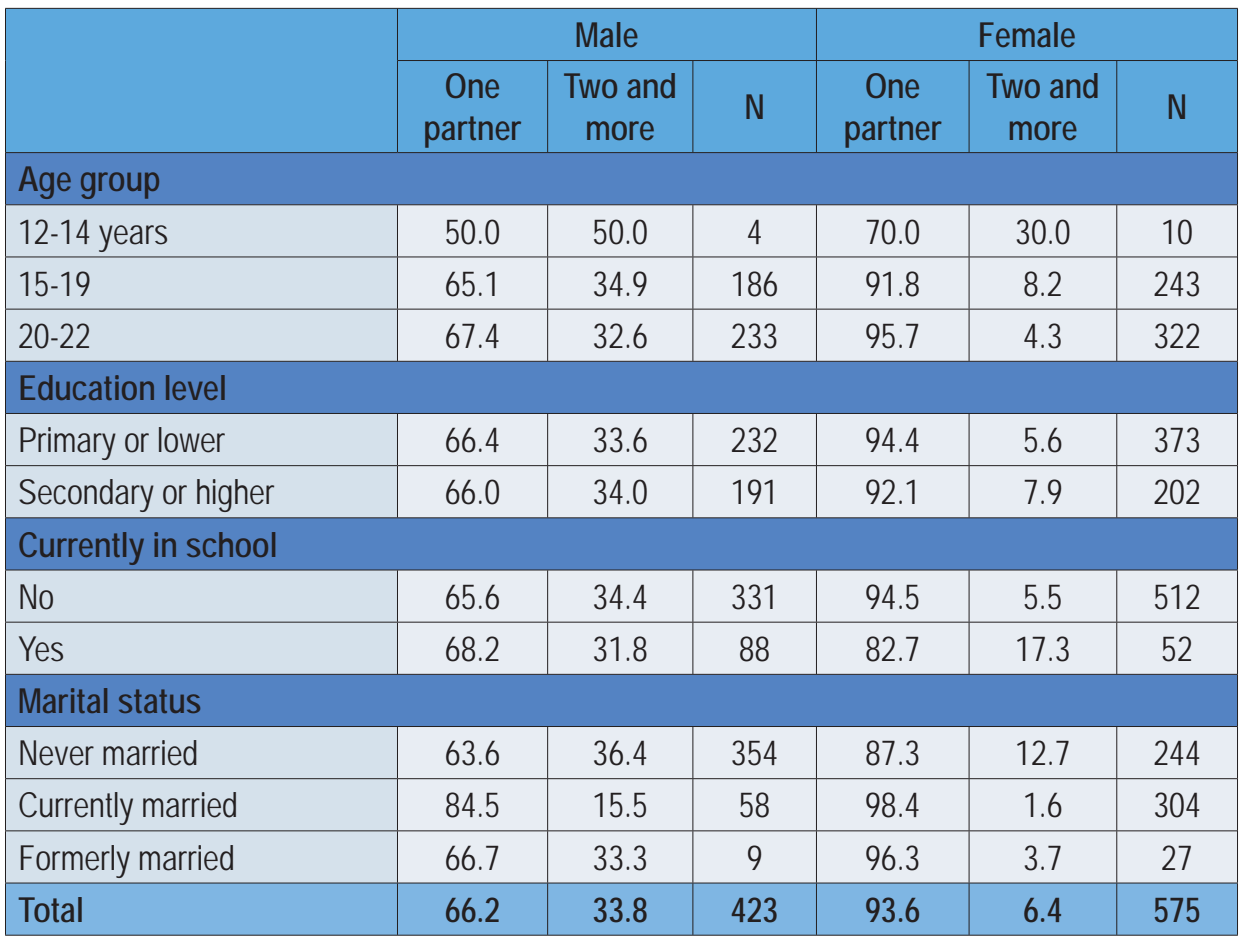

Source: TTA, Wave 1 data

\subsection{Circumstances of Sexual Debut}

Our data (Table 16) shows that adolescent girls were more likely to have had their first sexual experience with a co-habiting partner than their male peers. Also, out of school adolescents were twice as likely for males and nearly five times as likely for females, to have had their first sexual encounter with a co-habiting partner. Not surprisingly, married adolescents by far had the highest percentage of sexual debut with a co-habiting partner at $31 \%$ for males and $49 \%$ for females. 
Table 16. Percentage of adolescents who had first sexual intercourse with a cohabiting partner, by socio- demographic characteristics

\begin{tabular}{|c|c|c|c|c|}
\hline & Male & $\mathrm{N}$ & Female & $\mathrm{N}$ \\
\hline \multicolumn{5}{|l|}{ Age group } \\
\hline $12-14$ years & 14.3 & 21 & 25.0 & 20 \\
\hline $15-19$ & 7.8 & 296 & 18.9 & 302 \\
\hline $20-22$ & 13.3 & 331 & 34.6 & 382 \\
\hline \multicolumn{5}{|l|}{ Education level } \\
\hline Primary or lower & 11.4 & 360 & 29.9 & 455 \\
\hline Secondary or higher & 10.1 & 288 & 23.3 & 249 \\
\hline \multicolumn{5}{|l|}{ Currently in school } \\
\hline No & 12.4 & 476 & 29.3 & 611 \\
\hline Yes & 6.6 & 166 & 6.3 & 79 \\
\hline \multicolumn{5}{|l|}{ Marital status } \\
\hline Never married & 8.2 & 571 & 6.4 & 343 \\
\hline Currently married & 31.3 & 64 & 48.9 & 319 \\
\hline Formerly married & 25.0 & 12 & 39.0 & 41 \\
\hline Total & 10.8 & 648 & 27.6 & 704 \\
\hline
\end{tabular}

Source: TTA, Wave 1 data

Adolescents were asked whether they used contraceptives during their first sexual experience (Table 17). Findings show that $29 \%$ of males and $26 \%$ of females used contraceptives during their first sexual intercourse. Those aged above 15 years were more likely to have used a contraceptive method than those below 15 years of age. Among females, the proportion of contraceptive users at first sexual encounter was higher among those aged 15-19 than among those aged 20-22 years. Adolescent girls and boys with secondary education level or higher were more likely to use contraceptives during their first sexual encounter than those with lower education, with the gap being wider among females. Adolescent females who were still in school were more likely to have used contraceptives at sexual debut whereas the reverse was observed among males. The proportion of adolescents who had used contraceptives during their first sexual encounter was comparatively high among unmarried adolescents for both genders. 
Table 17. Percentage distribution of adolescents aged 12-22 years who used a contraceptive method at their first sexual encounter, by socio-demographic characteristics

\begin{tabular}{|c|c|c|c|c|c|c|}
\hline & \multicolumn{3}{|c|}{ Male } & \multicolumn{3}{|c|}{ Female } \\
\hline & No & Yes & $\mathrm{N}$ & No & Yes & $\mathrm{N}$ \\
\hline \multicolumn{7}{|l|}{ Age group } \\
\hline $12-14$ years & 95.2 & 4.8 & 21 & 85.0 & 15.0 & 20 \\
\hline $15-19$ & 69.7 & 30.3 & 297 & 70.4 & 29.6 & 304 \\
\hline $20-22$ & 70.1 & 29.9 & 331 & 76.4 & 23.6 & 385 \\
\hline \multicolumn{7}{|l|}{ Education level } \\
\hline Primary or lower & 72.3 & 27.7 & 361 & 81.7 & 18.3 & 459 \\
\hline Secondary or higher & 68.8 & 31.3 & 288 & 60.0 & 40.0 & 250 \\
\hline \multicolumn{7}{|l|}{ Currently in school } \\
\hline No & 69.4 & 30.6 & 477 & 75.9 & 24.1 & 615 \\
\hline Yes & 74.1 & 25.9 & 166 & 55.7 & 44.3 & 79 \\
\hline \multicolumn{7}{|l|}{ Marital status } \\
\hline Never married & 69.4 & 30.6 & 572 & 62.7 & 37.3 & 346 \\
\hline Currently married & 79.7 & 20.3 & 64 & 84.7 & 15.3 & 321 \\
\hline Formerly married & 83.3 & 16.7 & 12 & 85.4 & 14.6 & 41 \\
\hline Total & 70.7 & 29.3 & 648 & 74.0 & 26.0 & 709 \\
\hline
\end{tabular}

Source: TTA, Wave 1 data

Male condoms provide dual protection against sexually transmitted infections, such as HIVIAIDS, and pregnancy. As indicated in Table 18, about a quarter of the boys and a fifth of the girls indicated that they used condoms at their first sexual encounter. Male and female adolescents with at least secondary level of education were more likely than those with primary education or lower to have used condoms. Condom use at first sexual encounter was slightly more common among adolescent males who were not in school than among females although again, the small number of cases among in-school females warrants cautious interpretation. The proportion of adolescents who used condoms at first sexual encounter is highest among never married adolescents for both genders.

Table 18. Percentage of adolescents who used condom at their first sexual encounter, by socio-demographic characteristics

\begin{tabular}{|c|c|c|c|c|}
\hline & Male & $\mathbf{N}$ & Female & $N$ \\
\hline \multicolumn{5}{|l|}{ Age group } \\
\hline 12-14 years & 0.0 & 21 & 15.0 & 20 \\
\hline $15-19$ & 24.2 & 297 & 25.7 & 304 \\
\hline $20-22$ & 26.6 & 331 & 16.9 & 385 \\
\hline
\end{tabular}


Table 18. Percentage of adolescents who used condom at their first sexual encounter, by socio-demographic characteristics (Cont.)

\begin{tabular}{|c|c|c|c|c|}
\hline & Male & $\mathrm{N}$ & Female & $\mathrm{N}$ \\
\hline \multicolumn{5}{|l|}{ Education level } \\
\hline Primary or lower & 22.2 & 361 & 14.2 & 459 \\
\hline Secondary or higher & 27.8 & 288 & 32.4 & 250 \\
\hline \multicolumn{5}{|l|}{ Currently in school } \\
\hline No & 25.4 & 477 & 18.7 & 615 \\
\hline Yes & 22.9 & 166 & 38.0 & 79 \\
\hline \multicolumn{5}{|l|}{ Marital status } \\
\hline Never married & 25.9 & 572 & 31.2 & 346 \\
\hline Currently married & 15.6 & 64 & 10.6 & 321 \\
\hline Formerly married & 16.7 & 12 & 9.8 & 41 \\
\hline Total & 24.7 & 648 & 20.6 & 709 \\
\hline
\end{tabular}

Source: TTA, Wave 1 data

Adolescents reported several reasons why they used condoms (Figure 2). Overall, the majority of adolescent boys and girls reported having used condoms to prevent against both STI/HIV and pregnancy. These data merit further consideration in support of continued marketing of condoms for dual protection. No gender difference is observed as nearly equal proportions of males and females indicated that dual protection, followed by STI/ HIV protection (only) and pregnancy prevention (only) were the main reasons for using a condom at their first sexual encounter.

Figure 2. Percent distribution of adolescents according to the reasons why they used condom at first sex

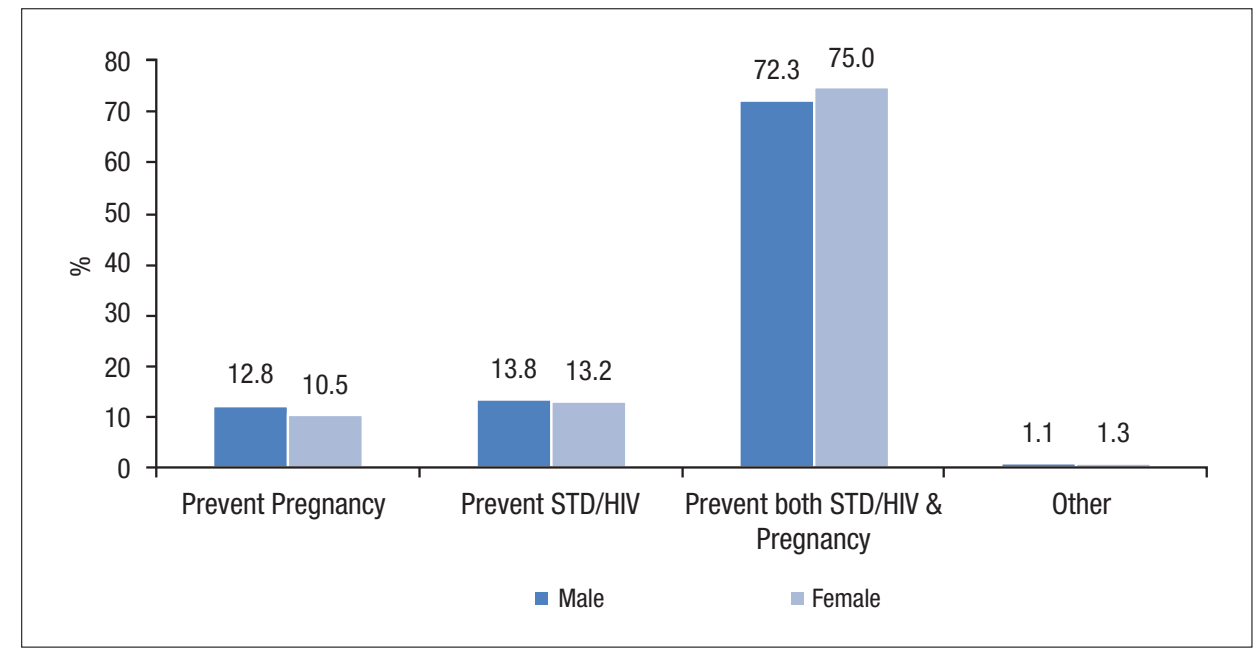

Source: TTA, Wave 1 data 
Figure 3 displays percentage distribution of adolescents according to their willingness to have a sexual debut. Overall, the majority of young men and women indicated they had been 'very willing' to engage in sex the first time they did so (81\% of males and $74 \%$ of females). Only very few adolescents girls and boys did not want to have sex the first time they did. In the in-depth interviews, two females reported that they had been forced or deceived into having their first sexual experience, as seen in their accounts below:

I didn't know anything and the guy (who) was more mature knew so much. I was just a naïve girl and didn't know what was going on but the guy was using me because he knew what he was doing. It was not good... my first experience was bad and painful and I didn't feel comfortable about it (Female, separated, 20 years)

Q: Why did you choose to have sex at that time?

A: He lied to me, that he will marry me (Female, single, 19 years)

Figure 3. Percent distribution of adolescents according to their willingness to initiate sex, by socio-demographic characteristics

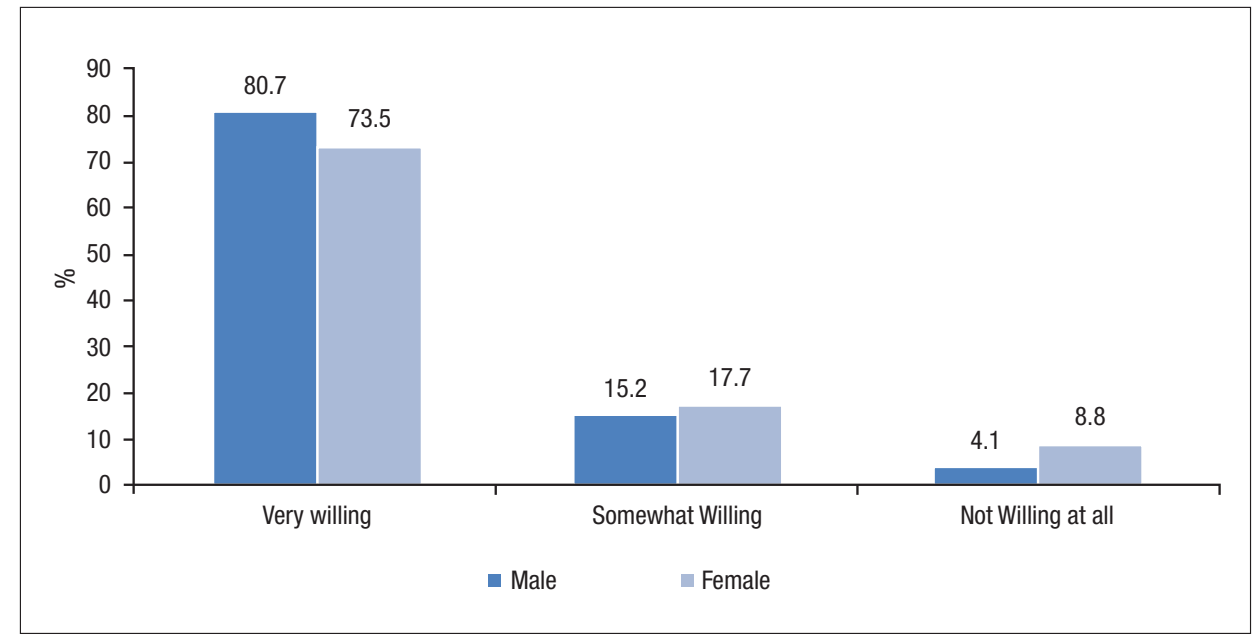

Source: TTA, Wave 1 data

\subsection{Circumstances of Most Recent Sexual Intercourse}

Table 19 shows the percentage of sexually active adolescents who had their last sexual intercourse with a cohabiting partner. Overall, young women were three times more likely to have had their most recent sexual experience with a cohabiting partner than young men. Older adolescents were also more likely to report that their most recent sexual experience was with a cohabiting partner. For example, the percentage of adolescent girls who had their last sexual encounter with a cohabiting partner was 40\% among 15-19 year olds compared to $64 \%$ among $20-22$ year olds. For boys, the corresponding percentage was $8 \%$ among $15-19$ year olds compared to $24 \%$ among $20-22$ year olds. 
Both adolescents with primary level of education or lower and out-of-school adolescents were more likely to have had their last sexual encounter with a cohabiting partner. As expected, the percentage of adolescents who had their last sexual encounter with a cohabiting partner was much higher among those who are married (close to $100 \%$ for both genders).

Table 19. Percentage of adolescents who had last sex with a cohabiting partner, by sociodemographic characteristics

\begin{tabular}{|c|c|c|c|c|c|c|}
\hline & \multicolumn{3}{|c|}{ Male } & \multicolumn{3}{|c|}{ Female } \\
\hline & No & Yes & $\mathbf{N}$ & No & Yes & $\mathrm{N}$ \\
\hline \multicolumn{7}{|l|}{ Age group } \\
\hline 12-14 years & 66.7 & 33.3 & 3 & 66.7 & 33.3 & 3 \\
\hline $15-19$ & 92.2 & 7.8 & 115 & 60.2 & 39.8 & 133 \\
\hline $20-23$ & 76.5 & 23.5 & 285 & 35.9 & 64.1 & 334 \\
\hline Total & 80.9 & 19.1 & 403 & 43.0 & 57.0 & 470 \\
\hline \multicolumn{7}{|l|}{ Currently in school } \\
\hline No & 78.0 & 22.0 & 327 & 40.1 & 59.9 & 434 \\
\hline Yes & 95.7 & 4.3 & 69 & 96.6 & 3.4 & 29 \\
\hline Total & 81.1 & 18.9 & 396 & 43.6 & 56.4 & 463 \\
\hline \multicolumn{7}{|l|}{ Education level } \\
\hline Primary or lower & 77.5 & 22.5 & 218 & 38.8 & 61.9 & 299 \\
\hline Secondary or higher & 83.8 & 15.2 & 184 & 51.0 & 47.9 & 169 \\
\hline Total & 80.8 & 19.2 & 402 & 43.2 & 56.8 & 468 \\
\hline \multicolumn{7}{|l|}{ Marital status } \\
\hline Never married & 98.4 & 1.6 & 310 & 96.7 & 3.3 & 183 \\
\hline Currently married & 2.9 & 97.1 & 70 & 2.0 & 98.0 & 246 \\
\hline Formerly married & 82.6 & 17.4 & 23 & 51.3 & 48.7 & 39 \\
\hline Total & 80.9 & 19.1 & 403 & 43.2 & 56.8 & 468 \\
\hline
\end{tabular}

Source: TTA, Wave 1 data

Condom use at last sexual intercourse was twice as high among males compared with females (Table 20). Results showed that 15-19 year-olds were more likely than 20-22 year-olds to report condom use during the most recent sexual encounter for both genders. None of the small sample of 12-14 year-olds reported any condom use, highlighting how adolescents with early sexual debut may be more likely to engage in risky sex. Education was positively associated with condom use at last sexual encounter, as boys and girls with at least secondary education were more likely to have used condoms during their last sexual encounter than their counterparts with primary education or lower. 
In addition, males and females who were in school were more likely to report condom use at their last sexual encounter than their out-of-school counterparts. The percentage of adolescents who used condoms during their last sexual encounter was also four to seven times higher among unmarried and formerly married adolescents than it was among their married counterparts.

Table 20. Percentage of adolescents who used condom at last sexual encounter, by sociodemographic characteristics

\begin{tabular}{|l|c|c|c|c|c|}
\hline \multirow{2}{*}{} & \multicolumn{3}{|c|}{ Male } & \multicolumn{2}{c|}{ Female } \\
\cline { 2 - 5 } Age group & Yes & N & Yes & N \\
\hline $12-14$ years & 0.0 & 3 & 0.0 & 3 \\
\hline $15-19$ & 56.9 & 116 & 30.1 & 133 \\
\hline $20-23$ & 42.6 & 284 & 22.3 & 332 \\
\hline Currently in school & \multicolumn{3}{|c|}{} \\
\hline No & 43.0 & 328 & 22.9 & 432 \\
\hline Yes & 66.2 & 68 & 48.3 & 29 \\
\hline Education level & & & & \\
\hline Primary or lower & 39.4 & 218 & 19.9 & 297 \\
\hline Secondary or higher & 54.3 & 184 & 32.5 & 169 \\
\hline Marital status & & & & \\
\hline Never married & 55.0 & 311 & 46.7 & 182 \\
\hline Currently married & 8.7 & 69 & 6.9 & 245 \\
\hline Formerly married & 43.5 & 23 & 30.8 & 39 \\
\hline Total & 46.4 & 403 & 24.4 & 468 \\
\hline
\end{tabular}

Source: TTA, Wave 1 data

Figure 4 indicates the reason why adolescents used a condom during their last sexual encounter. Overall, the majority of young men and women reported having used condoms to guard against STIS/HIV and pregnancy, though a greater proportion of males (78\%) than females $(65 \%)$ reported this dual use of condoms. Conversely, a greater proportion of females (26\%) than males (13\%) reported the use of condoms at their most recent sexual encounter to prevent pregnancy. 
Figure 4. Percent distribution of adolescents according to the reasons why they used condom at their last sexual encounter

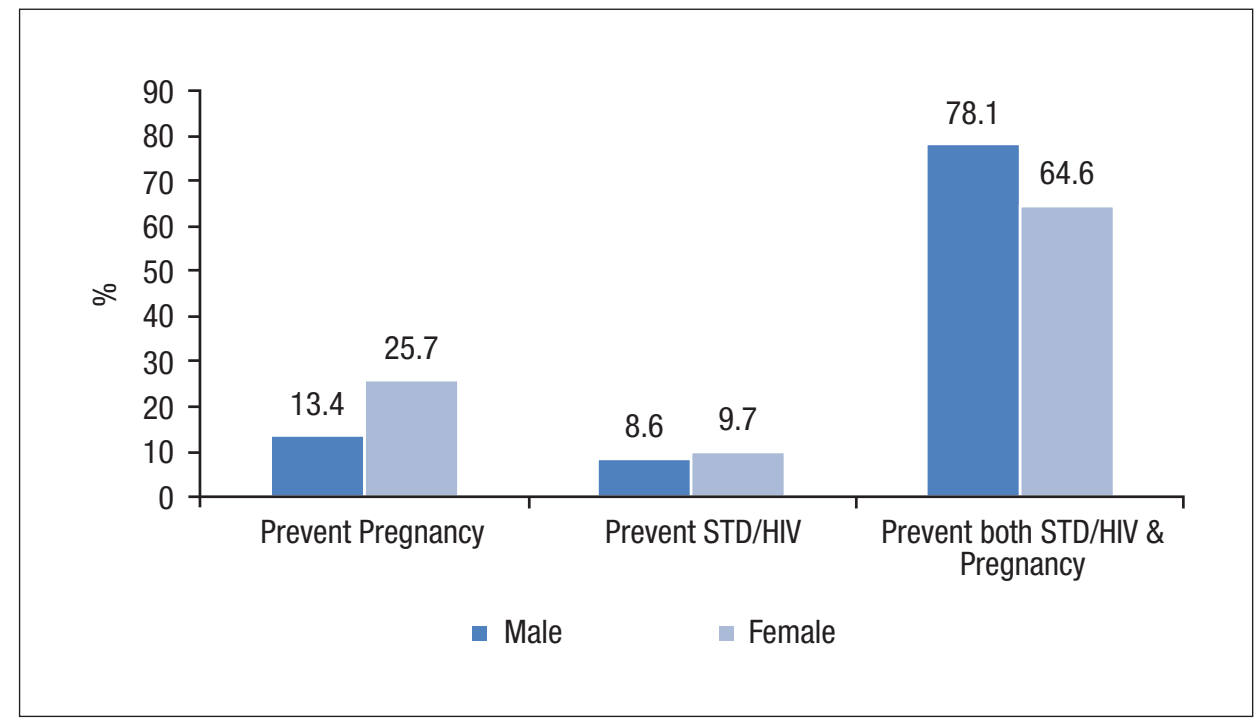

In Figure 5, we show the percentage of adolescents according to their willingness to have sex during their last sexual encounter. Overall, the majority of young men and women were 'very willing' to engage in sex the last time they did so, with boys being more likely to report so than girls. Only $1 \%$ of boys and $2 \%$ of girls were 'not willing at all' to have last sex during their last sexual encounter.

Figure 5. Percent distribution of adolescents according to their willingness to have the last sexual encounter

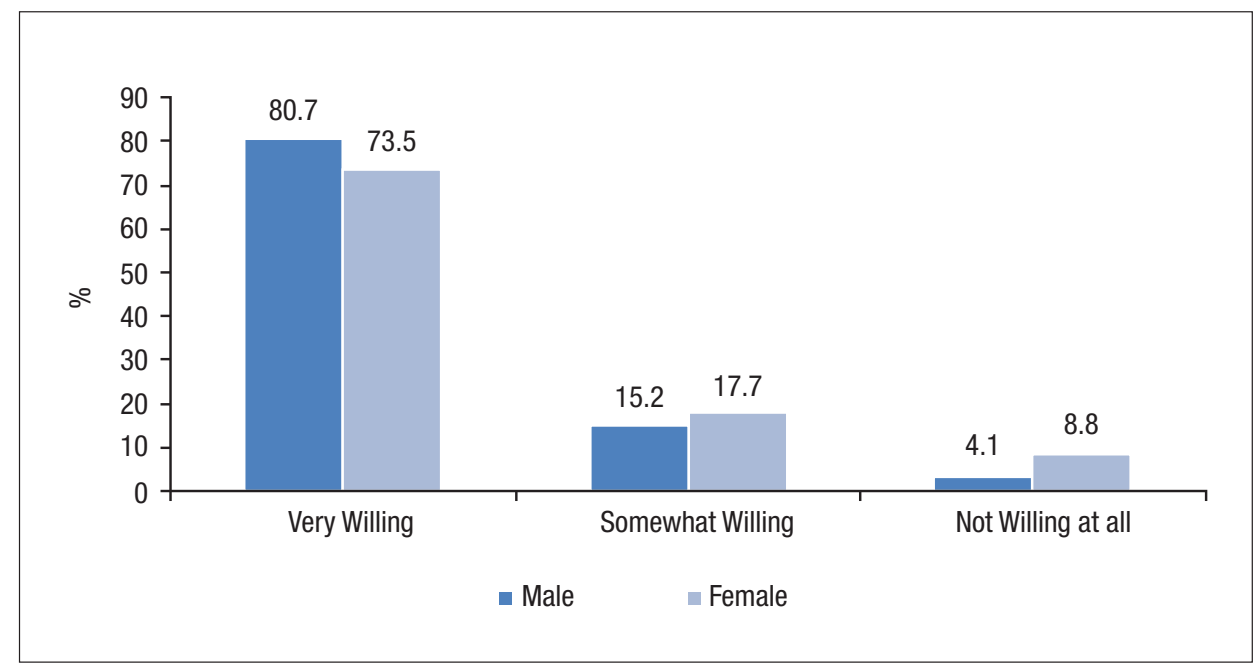




\subsection{Coercion into Sexual Activity}

During the survey, adolescents were asked the following question: 'Sometimes people do things to us we do not want. Has anyone ever touched you in an unwanted sexual way, such as kissing, grabbing or fondling?' In total, about $2 \%$ of boys and $5 \%$ of girls reported having been touched in a sexual way without their permission during their life (Table 21). Older adolescents were more likely to have had such an experience.

Table 21. Percentage of adolescents who have ever been touched in an unwanted sexual way, by socio-demographic characteristics

\begin{tabular}{|c|c|c|c|c|}
\hline & Male & $\mathrm{N}$ & Female & $\mathrm{N}$ \\
\hline \multicolumn{5}{|l|}{ Age group } \\
\hline 12-14 years & 0.8 & 609 & 3.3 & 578 \\
\hline $15-19$ & 1.6 & 928 & 7.0 & 886 \\
\hline $20-22$ & 4.0 & 471 & 4.9 & 494 \\
\hline \multicolumn{5}{|c|}{ Currently in school } \\
\hline No & 2.7 & 778 & 5.7 & 891 \\
\hline Yes & 1.5 & 1216 & 5.1 & 1042 \\
\hline \multicolumn{5}{|l|}{ Marital status } \\
\hline Never married & 2.0 & 1928 & 5.6 & 1600 \\
\hline Currently married & 1.6 & 63 & 3.5 & 317 \\
\hline Formerly married & 0.0 & 12 & 10.0 & 40 \\
\hline Total & 1.9 & 2008 & 5.4 & 1958 \\
\hline
\end{tabular}

Source: TTA, Wave 1 data

Adolescents were also asked whether anyone has physically forced, hurt or threatened them into having sexual intercourse. Overall, $3 \%$ of girls and about $1 \%$ of boys indicated that they had been coerced into having sex during their life (Table 22). The highest percentages were observed among $15-19$ and $20-22$ year-old females (4\% and 3\%, respectively). Out-of-school adolescents were also more likely to report coerced sexual intercourse. 
Table 22. Percentage of adolescents aged 12-22 years who have ever been physically forced or threatened into sexual intercourse, by age and schooling status

\begin{tabular}{|c|c|c|c|c|}
\hline & Male & $\mathrm{N}$ & Female & $\mathrm{N}$ \\
\hline \multicolumn{5}{|l|}{ Age group } \\
\hline 12-14 years & 0.0 & 609 & 0.9 & 577 \\
\hline $15-19$ & 0.9 & 927 & 4.0 & 886 \\
\hline $20-22$ & 1.3 & 471 & 2.8 & 493 \\
\hline Total & 0.7 & 2007 & 2.8 & 1956 \\
\hline \multicolumn{5}{|c|}{ Currently in school } \\
\hline No & 1.2 & 778 & 4.0 & 890 \\
\hline Yes & 0.3 & 1215 & 1.6 & 1041 \\
\hline Total & 0.7 & 1993 & 2.7 & 1931 \\
\hline
\end{tabular}

Source: TTA, Wave 1 data

The in-depth interviews reveal several accounts of women being coerced into sex in the two slums. Apart from being physically forced or threatened into sexual intercourse, females reported examples of young women being pressured into sexual relations with men by their parents, who expected monetary and other favors from the man in return. The quote below illustrates this kind of coercion:

"Sometimes you can meet a wealthy older man and maybe at home you don't have anything in terms of food and other basic necessities, you get some mothers encouraging the girls to get married to these old men so that he can provide for the family" (Korogocho, female, 17)

It is worth noting that many young women tended to perceive rape as a result of the victim's behavior. Among the cited behavior that they thought encouraged rape included provocative dressing, association with people of bad repute and being in locations perceived to be dangerous at late hours. The excerpts below exemplify these thoughts:

"Being raped is someone's doing because it happens when it is late. The girls ensure that they are not late." (Viwandani, female, 16 years)

"To me self-respect is the most important thing of all; you should know who you are socializing with, talking to and what are you talking about." (Viwandani, female, 23 years)

"[One should] dress appropriately so that you don't find yourself in compromising situations for example if you wear minis, it is easy for a man to rape." (Korogocho, female, widow, 21 years) 


\section{Reproductive Behavior and Unwanted Pregnancies}

\subsection{Initiation of Childbearing among Young Women}

The proportion of adolescents who have been pregnant is often used as a direct indicator of early childbearing. As shown in Table 23, 21\% of females had experienced a pregnancy, a proportion that increases to $61 \%$ if limited to sexually experienced young women. The proportion of females who had ever been pregnant was higher among the older clusters. Among sexually experienced females, $20 \%$ of $12-14$ year olds had been pregnant compared to $49 \%$ among $15-19$ year olds and $73 \%$ among $20-22$ year olds. Education was negatively associated with pregnancy experience, with those with primary education or lower being more likely to have ever been pregnant (72\% vs. $42 \%$ ) than their counterparts with at least secondary education. This is corroborated by the fact that the percentage of sexually active young women who have ever been pregnant is substantially higher among those who are out of school than those in school (68\% vs. $5 \%)$. This might suggest that pregnancy is a reason for being out of school. Not surprisingly, married females were more likely to have ever been pregnant.

Table 23. Percentage of female adolescents aged 12-22 years who have ever been pregnant, by socio-demographic characteristics

\begin{tabular}{|l|c|c|c|c|c|c|c|}
\hline \multirow{2}{*}{} & \multicolumn{3}{c|}{ All females } & \multicolumn{3}{c|}{ Females who ever had sex } \\
\cline { 2 - 7 } & No & Yes & N & No & Yes & N \\
\hline Age group & 99.2 & 0.8 & 589 & 80.0 & 20.0 & 20 \\
\hline $12-14$ years & 83.4 & 16.6 & 913 & 50.7 & 49.3 & 304 \\
\hline $15-19$ & 44.7 & 55.3 & 508 & 27.5 & 72.5 & 385 \\
\hline $20-22$ & 78.2 & 21.8 & 2010 & 38.9 & 61.1 & 709 \\
\hline Total & 75.7 & 24.3 & 1360 & 28.5 & 71.5 & 459 \\
\hline Education level & 83.4 & 16.6 & 650 & 58.0 & 42.0 & 250 \\
\hline Primary or lower & 78.2 & 21.8 & 2010 & 38.9 & 61.1 & 709 \\
\hline Secondary or higher & & & & & \\
\hline Total & 54.3 & 45.7 & 917 & 32.5 & 67.5 & 615 \\
\hline Currently in school & 99.5 & 0.5 & 1065 & 94.9 & 5.1 & 79 \\
\hline No & 78.6 & 21.4 & 1982 & 39.6 & 60.4 & 694 \\
\hline Yes & &
\end{tabular}


Table 23. Percentage of female adolescents aged 12-22 years who have ever been pregnant, by socio-demographic characteristics (Cont.)

\begin{tabular}{|l|c|c|c|c|c|c|}
\hline \multirow{2}{*}{} & \multicolumn{3}{c|}{ All females } & \multicolumn{3}{c|}{ Females who ever had sex } \\
\cline { 2 - 7 } & No & Yes & N & No & Yes & N \\
\hline Marital status & 92.4 & 7.6 & 1641 & 65.3 & 34.7 & 346 \\
\hline Never married & 14.5 & 85.5 & 325 & 13.4 & 86.6 & 321 \\
\hline Currently married & 18.6 & 81.4 & 43 & 17.1 & 82.9 & 41 \\
\hline Formerly married & 78.2 & 21.8 & 2009 & 39.0 & 61.0 & 708 \\
\hline Total &
\end{tabular}

Source: TTA, Wave 1 data

Table 24 shows the percentage of sexually experienced female adolescents who have ever had a child. Overall, 59\% of sexually experienced female respondents aged 12-22 had ever had a child. As expected, the proportion of females who had ever given birth was higher among the older clusters (46\% of 15-19 year old females had ever had a child compared to $71 \%$ among $20-22$ year olds).

Education is negatively associated with childbearing initiation with those having primary education or lower being more likely than their counterparts with at least secondary education to have ever had a child (69\% vs. 41\%). In addition, sexually experienced young women who were out of school were more likely to have had a child than their in- school counterparts (66\% vs. $1 \%$ ). Not surprisingly, married females were more likely to have had a child.

Table 24. Percentage of female adolescents who ever had a child, by socio-demographic characteristics

\begin{tabular}{|c|c|c|c|}
\hline \multicolumn{4}{|c|}{ Females who have ever had sex } \\
\hline & No & Yes & $\mathrm{N}$ \\
\hline \multicolumn{4}{|l|}{ Age group } \\
\hline $12-14$ years & 85.0 & 15.0 & 20 \\
\hline $15-19$ & 53.6 & 46.4 & 304 \\
\hline $20-22$ & 28.8 & 71.2 & 385 \\
\hline Total & 41.0 & 59.0 & 709 \\
\hline \multicolumn{4}{|l|}{ Education level } \\
\hline Primary or lower & 31.4 & 68.6 & 459 \\
\hline Secondary or higher & 58.8 & 41.2 & 250 \\
\hline Total & 41.0 & 59.0 & 709 \\
\hline
\end{tabular}


Table 24. Percentage of female adolescents who ever had a child, by socio-demographic characteristics (Cont.)

\begin{tabular}{|c|c|c|c|}
\hline \multicolumn{4}{|c|}{ Females who have ever had sex } \\
\hline & No & Yes & $\mathbf{N}$ \\
\hline \multicolumn{4}{|c|}{ Currently in school } \\
\hline No & 34.5 & 65.5 & 615 \\
\hline Yes & 98.7 & 1.3 & 79 \\
\hline Total & 41.8 & 58.2 & 694 \\
\hline \multicolumn{4}{|l|}{ Marital status } \\
\hline Never married & 67.1 & 32.9 & 346 \\
\hline Currently married & 16.2 & 83.8 & 321 \\
\hline Formerly married & 17.1 & 82.9 & 41 \\
\hline Total & 41.1 & 58.9 & 708 \\
\hline
\end{tabular}

Source: TTA, Wave 1 data

\subsection{Experience of Unwanted Pregnancies}

During Wave 1, young women were asked whether their last pregnancy was intended at the time of conception (planned), intended but at a later time (mistimed) or not intended at all (unwanted). Although responses to such questions should be cautiously interpreted because of possible post-rationalization, they give an idea of fertility planning status among young women in the slum communities. Table 25 shows the distribution of young women according to the planning status of their last pregnancy. Overall, about two-thirds of females' most recent pregnancies were planned, 17\% were mistimed and 19\% were unwanted. This means that, $36 \%$ of girls' most recent pregnancies were unintended.

For about a quarter of adolescents aged 15-19 years, their last pregnancy was unwanted, as compared to $16 \%$ among those aged $20-22$. On the contrary, the oldest of adolescents were more likely to have wanted their most recent pregnancy. There was not much difference based on education level. We could not compare the out-of-school and in-school adolescents due to the very small number girls in school who had ever been pregnant, likely reflecting the reality that, pregnancy is often the reason for leaving school. 
Table 25. Percent distribution of female adolescents according to the planning status of their last pregnancy, by socio-demographic characteristics

\begin{tabular}{|l|c|c|c|c|c|}
\hline \multirow{2}{*}{ Age group } & \multicolumn{4}{|c|}{ Planning status } \\
\cline { 2 - 5 } & Wanted & Mistimed & Unwanted & N \\
\hline $12-14$ years & - & - & - & 3 \\
\hline $15-19$ & 53.1 & 23.8 & 23.1 & 147 \\
\hline $20-22$ & 70.4 & 13.2 & 16.4 & 280 \\
\hline Education level & 64.7 & 15.8 & 19.5 & 323 \\
\hline Primary or lower & 62.6 & 19.6 & 17.8 & 107 \\
\hline Secondary or higher & \multicolumn{4}{|l}{} \\
\hline Currently in school & 63.9 & 16.9 & 19.1 & 413 \\
\hline No & - & - & - & 3 \\
\hline Yes & & & & \\
\hline Marital status & 32.8 & 27.7 & 39.5 & 119 \\
\hline Never married & 80.4 & 11.6 & 8.0 & 275 \\
\hline Currently married & 42.9 & 20.0 & 37.1 & 35 \\
\hline Formerly married & 65.1 & 16.0 & 18.9 & 375 \\
\hline Total &
\end{tabular}

Source: TTA, Wave 1 data

The in-depth interviews also indicate that some adolescents became pregnant even though they had not intended to become parents. Some adolescents acknowledged that they had not thought they could get pregnant when they engaged in sex, while others just said it was a 'mistake.' One male admitted that he forced his girlfriend to get pregnant because he envied his friends who had family, depicting situations where although one partner wants a child, the other might be against it and only obliges under pressure. The following excerpts reveal that adolescents engage in unprotected sex without expecting or planning to get pregnant:

Q: Why is getting pregnant so significant in your life?

A: I had not planned for it... I didn't expect to get pregnant. (Female, married, 21 years)

Q: You told me you got your first born at 16; did you plan for that pregnancy?

A: No, I didn't even know that I was pregnant, it was a mistake I had not planned to start having babies at that time I was still living with my parents and I wronged my father. (Female, married, 22 years)

We did not plan for it [the pregnancy] and it just happened and I didn't refuse because I was her only lover at that time. I was shocked; I didn't know what to say to her. 
She tried doing an abortion by asking me for money but I refused. (Male, single, 22 years)

Q: Did you plan for this pregnancy?

A: No, it came by coincidence... because we were not ready for a child and it just happened... back then I had not settled, I was not married, I was not ready for a kid (Female, Separated, 20 years)

Beyond shedding light on unintended pregnancies among adolescents, the interviews revealed that some coerce their lovers into getting pregnant to fulfill their own goals, as expressed by the adolescent below:

Q: Tell me about that pregnancy of your lover?

A: The girl was not ready but I had planned for it but the girl was not for it. I forced her and told her that we have been together for long and people will wonder what is wrong with us. She refused but I continued putting pressure on her until she accepted. We talked about it.

Q: Why did you decide to get a baby at that time?

A: Whenever I used to meet my friends, they all had children and the family looked nice, so I also longed for something like that. (Male, single, 22 years)

Economic pressure also contributes to the occurrence of unplanned pregnancies, as young women may have to exchange sexual favors for a job and, in the process they become pregnant. As one female adolescent put it:

My first [sexual intercourse] was under pressure and I didn't enjoy it. I had to do it to get a job...it was my first time to do it. I was also drunk and we didn't use any protection-that is why I got pregnant...it was not planned for. (Female, married, 23 years)

\section{FP/SRH Needs and Challenges Facing Urban Adolescents and Policy and Programmatic Implications}

\subsection{Summary and Discussion of Findings: FP/SRH Needs and Challenges}

Understanding the sexual and reproductive health of adolescents is of utmost importance and carries with it implications for improving individual health outcomes, especially reduction of unintended pregnancies and HIVISTIS. Young urban dwellers living in resource-poor settings are particularly vulnerable to poor sexual and reproductive health outcomes due to contextual and structural factors that impinge upon their ability to enjoy a healthy sexual and reproductive life $[2,5,8]$. Using data from adolescents in Nairobi's urban slums, we examined their levels of SRH knowledge, attitudes towards sex and contraception, and 
their sexual behavior. In assessing these indicators, we investigated their association with various socio-demographic characteristics. Overall, our findings underscore the significant challenges that adolescents in the slums face, especially with regard to lack of knowledge about sexual and reproductive health matters, attitudes that reflect prescribed ideologies and risky sexual behaviors that tend to increase adverse outcomes.

\section{Sexual and Reproductive Health Knowledge}

Although awareness of HIVIAIDS is almost universal among adolescents in our study, we noted substantial gaps in their understanding of sexual and reproductive knowledge. In particular, knowledge of the menstrual cycle was lacking, with only one in five females able to correctly identify the fertile period within the menstrual cycle regardless of their education levels. Qualitative results also highlight disconnects between SRH knowledge, attitudes and behavior among adolescents in the slums. Narratives from these adolescents generally indicate gaps between awareness and understanding. For example, adolescents were likely to report knowing about contraceptives and where to obtain them, yet hold misconceptions about contraceptive usage and effects that do not demonstrate an understanding of contraception.

Previous studies have highlighted limited menstrual knowledge among adolescents in diverse settings globally. In the United States, for example, Orringer and Gahagan's [10] study of a multi-cultural sample of post-menarcheal girls aged 11-19 found that most had an incomplete understanding of the physiological processes associated with menstruation. In northern Nigeria, a study conducted by Umar and colleagues [11] among in-school girls aged 10-19 years showed that although more than half of the girls knew that conception is possible within a certain window of the menstrual cycle, none could correctly identify the fertile window. A qualitative study conducted by Crichton and colleagues [12] among girls aged 12-17 years and their mothers in one of the slums also covered in the TTA study suggests that many girls lack comprehensive sexual and reproductive health information because of extensive barriers to open discussions between them and adults, particularly mothers. Mothers in the Crichton study reported discomfort, embarrassment, cultural taboos and lack of knowledge as significant barriers to talking with young girls about sexual and reproductive matters. Reaching out to key adults, such as parents and teachers, and equipping them with the skills to impart accurate knowledge to young people may therefore be an avenue for improving adolescents' sexual and reproductive health.

\section{SRH Attitudes}

Our results on adolescents' sexual and reproductive health-related attitudes reveal a complex range of influences on their beliefs, perceptions and attitudes. It was surprising to note that over $80 \%$ of respondents believed that both men and women should remain virgins until marriage. Yet, previous literature underscore differences in acceptable sexual conduct for young males and females in sub-Saharan Africa [13, 14], with premarital sexual activity being proscribed for girls, and boys' sexual experience being more readily accepted. There was, however a notable decrease in the proportion of adolescents holding this view as age increased among both genders. Further research elucidating the evolution of SRH attitudes with increasing age would be useful in shaping age-appropriate interventions. The qualitative interviews also revealed the complexity of the association 
between attitudes and behaviors. For example, although respondents placed value on abstinence or virginity before marriage, some practiced behavior that was contrary to these beliefs such as engaging in sexual intercourse at an early age or outside the confines of marriage. Likewise, in the quantitative study, a majority of young people agreed that it was a good idea to use condoms to prevent HIVIAIDS but less than one in four sexuallyexperienced adolescents reported condom use at their first intercourse. This indicates that although exposure to sexual and reproductive health messages may influence beliefs and attitudes, it is essential that programs do not just target transfer of knowledge but also find ways of translating generally acceptable attitudes and norms into individual private decisions and behaviors.

\section{HIV Testing and Counseling}

Knowledge of one's HIV status is likely to help an individual make decisions that may limit the risk or vulnerability of contracting or transmitting HIV. In our study, we found that a significant proportion of young men and women had been tested for HIV. However, there were substantial gender differences in HIV testing experiences. In particular, although a greater proportion of females than males had ever been tested for HIV, males were more likely to report the use of voluntary testing and counseling (VCT) services. These gender differences in HIV testing probably reflect the role of provider-initiated testing in the context of prevention of mother to child transmission of HIV (PMTCT) services. As reported in a study by Kabiru and colleagues [15] among TTA adolescents, about one in two females get tested because they are pregnant. Exploring the use of provider-initiated testing during routine healthcare visits, feasibility of which has been demonstrated in a limited range of settings [16, 17], might be one avenue to reach a greater pool of young men. It might also be worth exploring the acceptability of self-testing for HIV which provides privacy.

\section{Sexual Behavior}

Overall, we found that about three in ten adolescents aged between 12 to 22 years had engaged in sexual intercourse, though the proportion of sexually experienced adolescents varied significantly, as expected, with age and schooling status. Although the results indicate that sexual activity is largely an individual decision often accompanied by feelings of love and trust, the first sexual experience for a number of adolescents is coerced. About $3 \%$ of girls reported that they had ever been physically forced or threatened into having sexual intercourse; it is unacceptable that any portion of the population should experience forced, coerced or unwanted sex. The qualitative responses reveal elements of victimblaming in instances of sexual abuse, while in other cases, young girls are pressured into sexual relationships in order to meet household livelihood needs. Given the high possibility that experiences of sexual abuse are under-reported, these results indicate a need for increased attention to matters of sexual violence and abuse, particularly in resource-poor settings where young girls may be coerced into sexual relationships in order to meet basic needs.

Overall, the use of condoms and other contraceptives was quite low. Thus, it is not surprising that more than half of sexually- experienced girls had ever been pregnant with almost one in four of these pregnancies being reported as unintended. Notably, education was negatively associated with childbearing, with a substantially higher proportion of 
out-of-school girls reporting a previous pregnancy experience. Earlier studies in Kenya have reported that 13,000 girls drop out of school annually due to unintended pregnancy [18]. The fact that a higher proportion of-out of school girls reported a pregnancy may reflect the fact that those who become pregnant while in school drop out as a result of the pregnancy, though this directionality is only speculative. Moreover, the fact that married girls are less likely to use contraceptives but more likely to be sexually active and have a previous pregnancy could indicate that married adolescents are an extremely vulnerable segment of adolescents. Existing literature does posit that early family formation often has a negative impact on girls' autonomy, with little or no control of household resources. Taken together with the fact they are unlikely to be working or earning any income, their ability to decide how best to handle their reproductive needs, such as contraceptives to prevent unintended births [19] is severely limited.

Overall, therefore, the serious health risks of early fertility, especially among married and out-of school girls, and sexual activity in general provide greater impetus for addressing adolescent reproductive behaviors both within and outside of marriage. Overall, the use of condoms at first and most recent sexual encounter was low, particularly for females. Gender differences in condom use have been highlighted in previous studies conducted among African adolescents [20]. These differences have been ascribed to socio-cultural norms that frown upon sexual expression among females and deter them from obtaining, carrying or negotiating the use of condoms [13]. We also observed substantial gender differences in the reasons for condom use, with a greater proportion of females reporting condom use primarily to prevent pregnancy. Given that pregnancy and associated outcomes are particularly salient for adolescent girls, it is not surprising that prevention of pregnancy would be an important reason for females to use condoms. Among young people who had used condoms, almost three out of four reported condom use to prevent both pregnancy and HIVIAIDS. These reported levels of condom use for dual protection contrast substantially with levels reported in a 2009 study of young people in several African countries [21]. In this study, reported use of condoms for dual protection during most recent sexual encounter among young males aged 15-29 ranged from 1\% - 24\% when the sexual partner was a wife, girlfriend, or fiancée and from 4\%-35\% when the most recent sexual partner was a casual partner or commercial sex worker. That a substantial proportion of young people in our study reported the value of using condoms both for contraception and STI prevention is noteworthy given recent changes in the marketing of condoms not just for HIV prevention but also for contraception. Overall, this indicates that continued marketing of condoms targeting this group remains pertinent, useful and an effective strategy in the long term.

\section{Childbearing and Unintended Pregnancy}

Unintended pregnancies are associated with adverse health outcomes for both mother and child. A study conducted in the two slums, showed that abortion was a significant contributor to maternal mortality and was directly linked to about 31 percent of maternal deaths between 2003 and 2005 [22]. Previous studies have shown that women who report unintended pregnancy are less likely to seek antenatal care or to deliver with help of skilled attendants [23-25]. We observed a substantially higher burden of unintended pregnancies 
among certain subgroups of females. Among never-married females, two-thirds of last pregnancies were unplanned; among females aged 15-19 years, a quarter of pregnancies were unwanted and another quarter mistimed. Additionally, nearly every female who reported a pregnancy was out of school, suggesting that for females, pregnancy often leads to school drop-out. However, little is known or documented on what happens to unwanted or unintended pregnancies by adolescent females and further research is warranted.

\subsection{Policy and Programmatic Implications}

The results from this study point to the fact that there is a range of experiences among adolescents with regards to knowledge, attitudes and behaviors. Age, education and marital status were often strongly associated with certain adolescent sexual and reproductive health experiences. This highlights the fact that targeted programs are needed to reach adolescents with sexual and reproductive health services at different stages of need. There is no 'one size fits all' solution to address adolescent $\mathrm{SRH}$ needs; programs must consider ways to serve adolescents with comprehensive SRH information and services prior to sexual debut, as sexually active un-married adolescents, and as married individuals and couples. Attention should be paid to the wide variety of roles that adolescents play - whether students, workers, spouses or parents-in order to make SRH services accessible to this diverse population.

SRH programs for adolescents often target older adolescents, missing a key opportunity to intervene prior to initiation of sexual activity. The youngest group of adolescents in our study scored very low on knowledge indicators even though they were already engaging in risky sex. This underscores the need to strengthen sexual and reproductive health education for very young adolescents. Knowledge can be spread through a variety of media-school curricula, radio programs, youth groups-so it is imperative that programs identify channels that will reach this under-served population with comprehensive SRH information.

Despite reporting generally positive attitudes towards contraceptive use, adolescents' contraceptive use (including condoms) is low and unplanned pregnancies high, indicating a need for contraceptive services, especially among unmarried adolescents. This finding indicates the need to strengthen the provision of contraceptive services for adolescents. These programs should provide information and youth-friendly services for adolescents, and address the prevailing culture of stigma around adolescent sexual activity.

Ultimately, individual level factors are exacerbated by an environment affected by extreme poverty. For adolescents living in slums, poverty constrains the ability to access quality health information and services and may also contribute to coercive sexual relationships, particularly for young women [18]. Consistent and persistent poverty reduction strategies must therefore be considered alongside sexual and reproductive health services. Holistic programs that consider the relationship between health and environment are needed to address the complex web of factors that contribute to SRH. Opportunities for income generating activities among adolescents may reduce poverty, empower disenfranchised youth, and provide a forum for integration of SRH education and services. 


\section{References}

1. UN-HABITAT, The State of African Cities 2008 - A framework for addressing urban challenges in Africa2008, Nairobi: UN- HABITAT.

2. African Population and Health Research Center, Population and Health Dynamics in Nairobi's Informal Settlements: Report of the Nairobi Cross-sectional Slums Survey (NCSS) 2000, 2002, African Population and Health Research Center: Nairobi.

3. Mugisha, F. and E.M. Zulu, The influence of alcohol, drugs and substance abuse on sexual relationships and perception of risk to HIV Infection among adolescents in the informal settlements of Nairobi. Journal of Youth Studies, 2004. 7(3): p. 279-293.

4. Taffa, N., A comparison of pregnancy and child health outcomes between teenage and adult mothers in the slums of Nairobi, Kenya. International Journal of Adolescent Medicine and Health, 2003. 15(4): p. 321-9.

5. Zulu, E.M., F.N.-A. Dodoo, and A.C. Ezeh, Sexual risk-taking in the slums of Nairobi, Kenya, 1993-98. Population Studies, 2002. 56(3): p. 311-323.

6. Ezeh, A.C., I. Kodzi, and J. Emina, Reaching the Urban Poor with Family Planning Services. Studies in Family Planning, 2010. 41(2): p. 109-116.

7. Kabiru, C.W., et al., Transition into first sex among adolescents in slum and nonslum communities in Nairobi, Kenya. Journal of Youth Studies, 2010. 13(4): p. 453471.

8. Okonofua, F., New research findings on adolescent reproductive health in Africa. African Journal of Reproductive Health, 2007. 11(3): p. 7-9.

9. Stata Corporation, Stata/SE 12 for Windows2011, College Station, TX StataCorp LP.

10. Orringer, K. and S. Gahagan, Adolescent girls define menstruation: A multiethnic exploratory study. Health Care for Women International, 2010. 31(9): p. 831-847.

11. Umar, M.L., N.W. Yusuf, and A.B. Musa, Menstruation and menstrual hygiene amongst adolescent school girls in Kano, Northwestern Nigeria. African Journal of Reproductive Health, 2010. 14(3): p. 201-207.

12. Crichton, J., L. Ibisomi, and S.O. Gyimah, Mother-daughter communication about sexual maturation, abstinence and unintended pregnancy: Experiences from an informal settlement in Nairobi, Kenya. Journal of Adolescence, 2012. 35(1): p. 21-30.

13. MacPhail, C. and C. Campbell, 'I think condoms are good but, aai, I hate those things': Condom use among adolescents and young people in a Southern African township. Social Science \& Medicine, 2001. 52(11): p. 1613-1627.

14. Varga, C.A., How gender roles influence sexual and reproductive health among South African adolescents. Studies in Family Planning, 2003. 34(3): p. 160-172.

15. Kabiru, C., et al., HIVIAIDS among youth in urban informal (slum) settlements in Kenya: What are the correlates of and motivations for HIV testing? BMC Public Health, 2011. 11(1): p. 685.doi: 10.1186/1471-2458-11-685

16. Kiene SM, et al., Provider-initiated HIV testing in health care settings: Should it include client-centered counselling? Journal of Social Aspects of HIVIAIDS - Sahara Journal, 2009. 6(3): p. 115-119.

17. Leon, N., et al., Provider-initiated testing and counselling for HIV: From debate to implementation. SAMJ: South African Medical Journal, 2010. 100: p. 220-221. 
18. Muganda-Onyando, R. and O. Martin, Down the drain: Counting the cost of teenage pregnancy and school dropout in Kenya, 2008, Center for the Study of Adolescence: Nairobi.

19. Singh, S. and R. Samara, Early marriage among women in developing countries. International Family Planning Perspectives, 1996. 22(4): p. 148-157 \& 175.

20. Prata, N., F. Vahidnia, and A. Fraser, Gender and relationship differences in condom use among 15-24-Year-olds in Angola. International Family Planning Perspectives, 2005. 31(4): p. 192-199.

21. Bankole, A., et al., Condom use for preventing STI/HIV and unintended pregnancy among young men in Sub-Saharan Africa. American Journal of Men's Health, 2009. 3(1): p. 60-78.doi: $10.1177 / 1557988308322394$

22. Ziraba, A., et al., Maternal mortality in the informal settlements of Nairobi city: what do we know? Reproductive Health, 2009. 6(1): p. 6.

23. Fotso, J., et al., What does access to maternal care mean among the urban poor? Factors associated with use of appropriate maternal health services in the slum settlements of Nairobi, Kenya. Maternal and Child Health Journal, 2009. 13(1): p. 130-137.

24. Magadi, M.A., J.M. Nyovani, and R.N. Rodrigues, Frequency and timing of antenatal care in Kenya: Explaining the variations between women of different communities. Social Science and Medicine, 2000. 51(4): p. 551-561

25. Marston, C. and J. Cleland, Do unintended pregnancies carried to term lead to adverse outcomes for mother and child? An assessment of five developing countries. Population Studies, 2003. 57(1): p. 77-93. 



\section{www.stepup.popcouncil.org}

The STEP UP (Strengthening Evidence for Programming on Unintended Pregnancy) Research Programme Consortium generates policy-relevant research to promote an evidencebased approach for improving access to family planning and safe abortion. STEP UP focuses its activities in five countries: Bangladesh, Ghana, India, Kenya, and Senegal.

STEP UP is coordinated by the Population Council in partnership with the African Population and Health Research Center; icddr-b; the London School of Hygiene and Tropical Medicine; Marie Stopes International; and Partners in Population and Development. STEP UP is funded by UK aid from the UK Government. 